\title{
Association between cardiometabolic risk factors and COVID-19 susceptibility, severity and mortality: a review
}

\author{
Yasaman Sharifi ${ }^{1,2} \cdot$ Moloud Payab $^{3} \cdot$ Erfan Mohammadi-Vajari $^{4} \cdot$ Seyed Morsal Mosallami Aghili ${ }^{1} \cdot$ Farshad Sharifi $^{5}$. \\ Neda Mehrdad $^{6,7} \cdot$ Elham Kashani $^{8} \cdot$ Zhaleh Shadman $^{5} \cdot$ Bagher Larijani $^{1} \cdot$ Mahbube Ebrahimpur $^{5}(0$
}

Received: 31 January 2021 / Accepted: 23 May 2021 / Published online: 26 June 2021

(c) Springer Nature Switzerland AG 2021

\begin{abstract}
The novel coronavirus, which began spreading from China Wuhan and gradually spreaded to most countries, led to the announcement by the World Health Organization on March 11, 2020, as a new pandemic. The most important point presented by the World Health Organization about this disease is to better understand the risk factors that exacerbate the course of the disease and worsen its prognosis. Due to the high majority of cardio metabolic risk factors like obesity, hypertension, diabetes, and dyslipidemia among the population over 60 years old and higher, these cardio metabolic risk factors along with the age of these people could worsen the prognosis of the coronavirus disease of 2019 (COVID-19) and its mortality. In this study, we aimed to review the articles from the beginning of the pandemic on the impression of cardio metabolic risk factors on COVID-19 and the effectiveness of COVID-19 on how to manage these diseases. All the factors studied in this article, including hypertension, diabetes mellitus, dyslipidemia, and obesity exacerbate the course of Covid-19 disease by different mechanisms, and the inflammatory process caused by coronavirus can also create a vicious cycle in controlling these diseases for patients.
\end{abstract}

Keywords COVID-19 · Cardio Metabolic Risk Factors · Dyslipidemia · Diabetes mellitus · Hypertension · Obesity

\section{Introduction}

The latest pandemic of the coronavirus has affected all components of the human lifestyles and has unfolded the sickness rapidly at some stage in the world. The coronavirus disease of 2019 (COVID-19) has been recognized as 2019-nCOV. This novel virus motives COVID-19 ailment

Moloud Payab

moloudpayab@gmail.com

Mahbube Ebrahimpur

m-ebrahimpur@tums.ac.ir

1 Endocrinology and Metabolism Research Center, Endocrinology and Metabolism Clinical Sciences Institute, Tehran University of Medical Sciences, Tehran, Iran

2 Yaas Diabetes and Metabolic Diseases Research Center, Indiana University School of Medicine, Indianapolis, IN 46202, US

3 Metabolomics and Genomics Research Center, Endocrinology and Metabolism Molecular-Cellular Sciences Institute, Tehran University of Medical Sciences, Tehran, Iran that has comparable signs and symptoms as severe acute respiratory syndrome coronavirus 2 (SARS-COV2) [1]. Since April 10, 2021, a total number of 135 Million cases of COVID-19 occurring in at least 170 countries and territories were reported with relatively $3-4 \%$ of fatality rate. [2]. Although not all factors affecting mortality and severity of COVID-19 disorder have now been identified, studies have

4 Student of Medicine, School of Medicine, Gilan University of Medical Sciences, Rasht, Iran

5 Elderly Health Research Center, Endocrinology and Metabolism Population Sciences Institute, Tehran University of Medical Sciences, Tehran, Iran

6 Diabetes Research Center, Endocrinology and Metabolism Clinical Sciences Institute, Tehran University of Medical Sciences, Tehran, Iran

7 Nursing Care Research Center, Iran University of Medical Sciences, Tehran, Iran

8 Department of Obstetrics and Gynecology, Golestan University of Medical Sciences, Golestan, Iran 
shown that the majority of mortality were amongst patients of $>60$ [2].According to previous studies, the prevalence of cardio metabolic risk factors like obesity, diabetes mellitus, hypertension and dyslipidemia in people over 60 years old are significantly higher [3]. Hypertension (HTN) is one of the main cardiovascular comorbidities, but it is still unclear whether the association between HTN and COVID-19 is independent from advanced age or not [4]. SARS COV2 gains entrance to cells through the angiotensin converting enzyme 2(ACE2) [5]. On the same basis, there are many concerns about taking Angiotensin converting enzyme inhibitors (ACEI)/Angiotensin Receptor Blocker (ARB) drugs and making the patient more susceptible to viral host cell entry and propagation [6-9]. Diabetes mellitus (DM) is another cardio metabolic risk factor that seems to be an important factor that changes the severity of the COVID19 disease [10-13]. Infections especially pneumonia and influenza Hemagglutinin Type 1 and Neuraminidase Type 1 (H1N1), are more common and more severe in patients with type 2 diabetes [13-15]. There are several studies on the effects of SARSCOV2 which trigger higher stress conditions leading to hyperglycemia in diabetic patients [16]. Therefore the effects of inflammatory status and changes in the immune system as well as the effect of SARSCOV2 virus on insulin secretion in diabetic patients are still unknown [15]. Reviewing studies will help better control diabetes during the coronavirus pandemic. Dyslipidemia is a critical risk factor of the current approach to cardiovascular disease (CVD) risk management $[17,18]$. Among different levels of dyslipidemia which include elevated low-density lipoprotein (LDL), cholesterol levels, or low levels of high-density lipoprotein (HDL) [19], low HDL_C is a strong predictor of CVD progression [18]. Based on the multiple roles of HDL_C in modulating the immune system, antithrombotic, and antioxidants, the use of drugs effective in increasing HDL_C levels can suppress the coagulation cascade as well as platelets over activity, which play a role in the exacerbation of COVID-19 disease and its morbid complications [20]. Obesity is the last cardio metabolic risk factor addressed in the present research. Obesity is commonly defined by body mass index (BMI) [21], and importantly this epidemic disease of the last century has been associated with other cardiovascular diseases, insulin resistance, type 2 diabetes and several cancers [22, 23]. In addition to the role of obesity in reducing the immune responses, causing chronic inflammation, metabolic dysfunction, it is associated with a large number of comorbidities, and the mesenchymal dysfunction in obese patients can exacerbate the cytokine storm caused by COVID-19 disease and promoting pulmonary fibrosis leads to severe form of the disease [24]. Due to the high incidence of cardio metabolic risk factors in the world population and other roles in changing the course of many diseases, in this study, which is a narrative review article [3], we decided to review the role of COVID-19 and recent pandemic in altering these risk factors such as HTN, DM, dyslipidemia and obesity along with the impact of these metabolic comorbidities in the course of COVID-19 disease in infected people.

\section{Cardio metabolic risk factors and COVID-19 fatality}

The recent crisis that has gripped the world is the outbreak of the novel COVID-19 disease and its rapid worldwide spread. The novel virus is thought to belong to the same family as the Middle East respiratory syndrome (MERS) coronavirus and severe acute respiratory syndrome (SARS) coronavirus, but it is unique in its way [25]. As the main concern of all researchers around the world is several risk factors that cause the severity of COVID-19. The World Health Organization (WHO) indicated that elderly patients, as well as those with underlying medical conditions, are at higher risk of developing severe COVID-19 disease [26]. As of today 10 April, 2021, over 135 million cases are infected by the virus and more than 2.9 million people have lost their lives. Most of the death and severe cases of the disease are believed to be associated with the underlying comorbidities [27].

\section{Introduction to COVID-19 and hypertension}

The coronavirus caused a pandemic worldwide with the severe acute respiratory syndrome and a very high rate of transmission. Comorbidities associated with this infectious disease play an important role in the severity of the disease and its mortality in the affected individuals. High blood pressure (hypertension) is one of the most common comorbidities in severe COVID-19 patients [28]. There are different studies on the association between the severity of COVID-19 disease in people with hypertension and also the higher incidence of this virus in these people. The association between HTN and developing pneumonia was assessed in the UK biobank data of 107,310 patients with high blood pressure with $3 \%$ of them developing pneumonia afterward. The data analysis of this study revealed that the risk of respiratory disease is remarkably higher among patients with HTN. These patients were also considered to be at a greater risk of acute and chronic respiratory disease, independent of age, sex, smoking status and BMI. Generalizing these results to COVID-19 is rational and led to many studies that focus on hypertension as a strong indicator of COVID-19 severity[29]. Guan et al. reported data from 1099 confirmed COVID-19 patients, of which the single highest risk factor of infection was HTN in $15 \%$ of patients. Among patients with severe form of the disease (173 cases) the 
most frequent co-morbidity was $\operatorname{HTN}(23.7 \%)$, and $35.8 \%$ of patients demanding intensive care unit(ICU) admission, and mechanical ventilation or those who expired also had HTN as an underlying condition [30].

\section{- Pathophysiological link between hypertension and COVID-19}

High pressure level (also stated as HBP or hypertension) is when your pressure, the force of blood flowing through your blood vessels, is consistently too high.

Hypertension is a controllable and common risk factor for cardiovascular diseases. The reported prevalence of hypertension varies around the world, with rock bottom prevalence in rural India (3.4\% in men and 6.8\% in women) and accordingly the highest prevalence in Poland(68.9\% in men and $72.5 \%$ in women) [31]. Its estimated that 1.13 billion people worldwide are suffering hypertension, most (two-thirds) living in low- and middle-income countries [32]. In Iran the estimated prevalence of hypertension in $30-55$ and $>55$-year-old population are around $23 \%$ and $50 \%$, respectively. The prevalence in men was $1.3 \%$ less than that in women [33]. One of the most commonly used treatments for hypertensive patients is angiotensin converting enzyme inhibitors (ACEI) or Angiotensin Receptor Blocker(ARB), with $50 \%$ of the hypertensive population in the United States using these drugs to control their blood pressure [34]. Preliminary reports from the Wuhan and New York Centers showed that there was a high prevalence of hypertension among people with severe illness as well as hospitalized patients [35, 36]. The predominance of hypertension in studies conducted in several countries, including the United States, China and Italy, showed similar prevalence among COVID-19 infected patients, as $56 \%, 50 \%$ and $49 \%$, respectively. This implies that about 50\% of COVID-19 infected patients have a history of hypertension [35, 37, 38]. Despite these observations, the association between hypertension and COVID-19 still remains unclear. While overrepresentation of high blood pressure is seen in patients admitted to hospitals COVID-19, it is uncertain whether this connection is due to the older age of these patients and the presence of other comorbidities including obesity, diabetes mellitus, and chronic kidney disease, or this is just a simple random association. The reason behind the association between HTN and severe form of COVID-19 was evaluated in the study of Kulkarni et al. in which this association was attributed to prevalence of hypertension in older individuals. According to CDC reports about $63 \%$ of people over 60 years old are hypertensive [39]. However an alternative explanation is end organ damage in hypertensive patients. Two common complications of
HTN are left ventricular hypertrophy and fibrosis which may make the hypertensive heart considerably vulnerable to SARS-COV2 [40]. The theory of virus (SARS-COV2) entry into host cells via angiotensin converting enzyme 2(ACE2) raised doubts about continuing treatment with ACEI or ARB or discontinuing them in patients with underlying hypertension [41]. Human angiotensin converting enzyme2 (ACE2) is an endothelium bound carboxymonopeptidase with single active site catalytic region whose expression is restricted mainly to endothelial cells of the arteries, arterioles and venules in different organs such as the heart, lungs and kidneys [42]. Figure1 shows the RAAS ${ }^{1}$ cascade.

\section{- COVID-19 and Interaction with Renin-Angiotensin Aldosterone System Inhibitors}

ACE2 plays an important role in several cardiovascular and immune pathways. The binding affinity of the novel coronavirus with ACE2 appears to be stronger than SARS virus which could explain the considerably higher global influence of COVID-19 than the initial SARS [43]. The research of Chen et al. recently identified that human cardiac pericytes have high expression of ACE2 which could also be the target cells of SARS-COV2. Patients with heart failure showed elevated ACE2 expression at both mRNA and protein levels, which further raises the risk of heart attack and the critically ill conditions in patients infected by SARS-COV2 [44].

\section{- Impact of Renin-Angiotensin Aldosterone System Inhibitors on COVID-19 outcome}

The usage of ACEI (angiotensin converting enzyme inhibitors) and ARB (angiotensin 2 receptor blocker) in the setting of SARS-COV2 infection is a hypothesis which is supported by these findings: 1.replication of a prominent effect in multiple animal studies and models 2. It is revealed that tissues with low expression of ACE2 following the treatment with ACEI/ARB show a considerable increase in their expression of ACE2. 3. Sufficient data is available that the increase in ACE2 expression in response to ACEI/ARB treatment enhances the ability of SARS-COV2 to infect cells 4.epidemiological data have shown that patients with COVID-19 administrated ACEI/ARB have increased morbidity and mortality. But these findings have not been supported by sufficient evidence and reports in further studies [36, 45-49]. The findings of the research of Sriram et al. as a literature review of studies in experimental animals and human

$\overline{1 \text { renin-angiotensin-aldosterone system. }}$ 


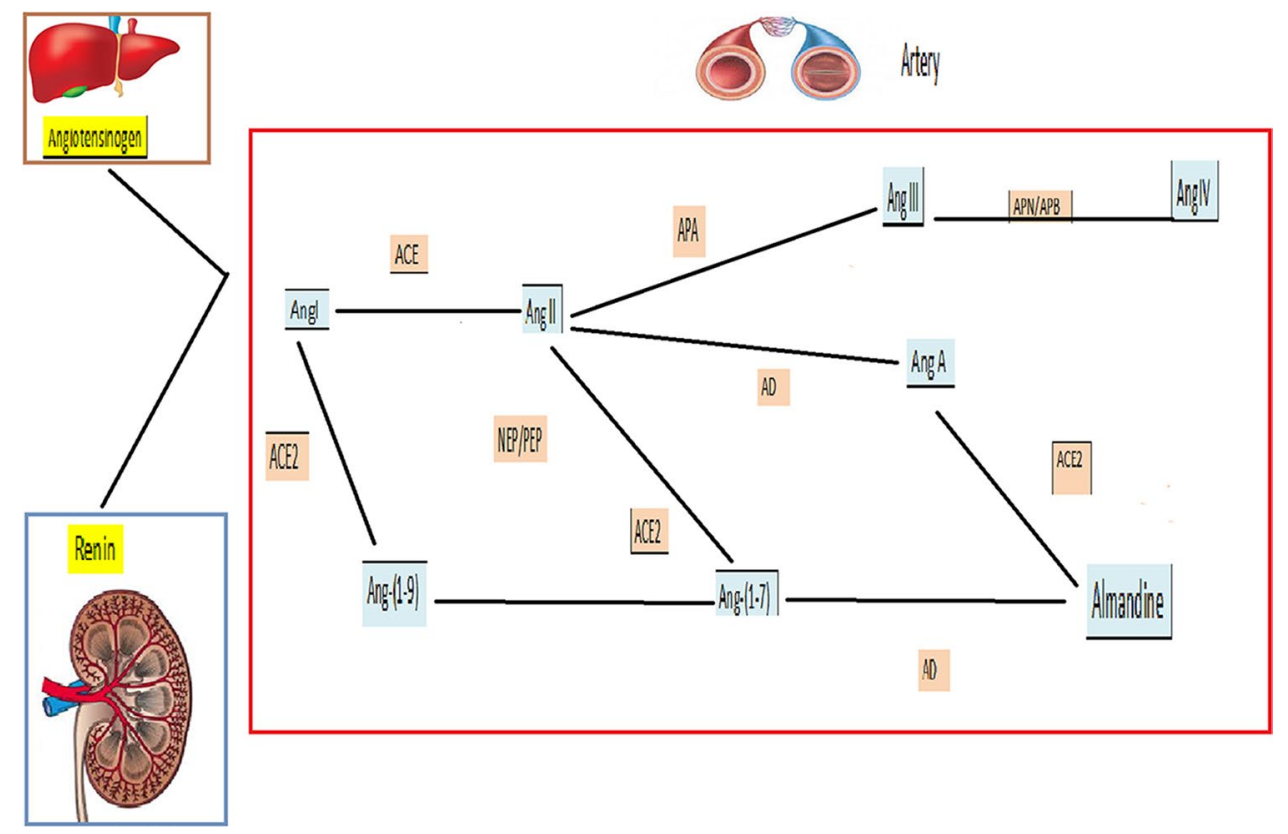

Fig. 1 The Renin angiotensin system cascade: first the liver produces angiotensinogen (AGT) which is secreted in sinusoidal capillaries. Renin is an enzyme produced by juxtaglomerular apparatus of the kidney which is also secreted in the circulation. In the blood stream, angiotensinogen is cleaved by Renin into Ang1, which can also split by ACE2, producing Ang-1-9 by NEP(neutral-endopeptidase) or PEP, producing Ang (1-7) and bye ACE and synthesize Ang-(1-7)

objects $(\mathrm{n}=12)$ and evaluating the evidence regarding the impact of administration of ACEI/ARB on ACE2 expression revealed inconsistent effects of RAAS inhibitors on ACE2 levels. Also the hypothesis that use of these drugs would increase SARS-COV2 virus infectivity and/or severity of COVID-19 is therefore not approved by current information recommending the continuation of using ACEI/ARB [50]. On the other hand, many cases of myocardial infarction, myocarditis and cardiomyopathy have been reported in COVID-19 patients and discontinuation of cardio protective drugs, including RAAS inhibitors can lead to clinical heart decompensation [51].

The remarkable point is that a study that investigated COVID-19 patients with HTN treated with ACEI/ARB confirmed that patients receiving ACEI/ARB therapy had a lower risk of the severe form of COVID-19 and also decreased level of IL-6 in their peripheral blood. Moreover, it showed that ACEI/ARB therapy increased the level of CD3 and CD8 T-cells in peripheral blood and reduced the peak viral load compared to other antihypertensive drugs. These findings were the first evidence that supports the benefit of ACEI/ARB in COVID-19 patients. The authors assumed that RAAS inhibitors did not directly inhibit the viral replication but had an indirect antiviral role by regulating the immune system and inhibiting of the inflammatory response [52]. or it can be cleaved by APA(aminopeptidase) producing Ang III. Ang II can still have its first amino acid replaced, forming Ang A, which can be cleaved by ACE2 into almandine. This heptapeptide almandine can also be formed by Ang-(1-7) due to the replacement of one amino acid. Ang III can be cleaved by APN (aminopeptidaseN) and form AngIV

In a retrospective cohort study conducted in 17 referred hospitals affiliated to Iran University of Medical science (IUMS) between February 20th and April 4th 2553 patients with COVID-19 were recruited among which 1569 (61.5\%) patients had a history of an underlying diseases. There were 710 patients with history of HTN (45.3\%) and among all patients $83(3.3 \%)$ received ACEI, 444(17.4\%) received ARB. According to the findings of this study administration of ACEI/ARB in COVID-19 patients with concurrent HTN will lead to improvement of clinical outcomes and these medications can be potential therapeutic options and increases the survival probability in these cases [53].

In a retrospective multicenter study by Zhang et al. 1128 adult patients with HTN diagnosed with COVID19, among which 188 were taking ACEI/ARB and 940 without using them admitted to 9 hospitals in Hubei province, china from December 312019 to February 202020 were recruited. After adjusting confounding components such as age, gender, comorbidities, and inhospital drugs, the detected hazard for all-cause mortality was lower within the ACEI/ARB group versus the nonACEI/ARB group. The results of the study also demonstrated lower risk of COVID-19 mortality in patients who received ACEI/ARB [54]. 
In a systematic review and met analysis which consisted of 18 studies comparing the occurrence of severe COVID-19 in infected hypertensive patients who received ACEI/ARB vs no treatment or other antihypertensive drugs with 17,311 patients revealed that the use of RAS inhibitors was associated with a significant $16 \%$ decreased risk of the combined outcome (death, admission to ICU, mechanical ventilation requirement or progression to severe or critical pneumonia) $\mathrm{RR}=0.84(95 \% \mathrm{Cl}: 0.73-0.95) . \mathrm{P}=0.007, \mathrm{I}^{2}=65 \%$ [55].

Another systematic review evaluating the association between different underlying disease and COVID-19 severity and fatality showed that like diabetes, hypertension has been proven to be linked to a significantly higher chance of respiratory infection, making it a substantial indicator of COVID-19 severity.[56]Furthermore this study demonstrated that hypertension is a common comorbidity in COVID-19 death cases as well as higher rate of ICU admission. According to this review similar to other studies mentioned earlier, hypertension treatment should be continued to lower the risk of severity [25].

\section{- Hypertension and COVID-19 in brief}

To give an abstract of what have been reviewed in this research, HTN is one of the most common comorbidities in COVID-19 patients confirmed by several studies and this condition also plays an important role in exacerbating the infection with SARS-COV2 and leads to higher rate of mortality, ICU admission and the requirement of mechanical ventilation. The theory of ACE receptors which facilitate the entry of SARS-COV2 in their target cells also has been studied abundantly and the effect of RAAS inhibitor drugs like ACEI/ARB on severity and fatality of COVID-19 patients with hypertension are continuously evaluated. Reviewing these studies showed that administration of ACEI/ARB decreases the severity and fatality of COVID-19 significantly and there seems to be a general agreement with most health organizations, who suggested HTN treatments such as ACEI/ARB should be continued in patients with SARS-COV2 infection. In "Table 1" we reviewed several articles investigating the consequences of antihypertensive medications and also the incidence of COVID-19 in these patients. There is still a controversy about the use of these drugs (ACEI/ ARB) as a prevention of severe form of COVID-19.

\section{Introduction to COVID-19 and diabetes}

Since the outbreak of novel COVID-19 disease and the problems caused by this pandemic, researchers turned their attention to the factors that contribute to the exacerbation or mortality of the disease. Among these comorbidities, diabetes has been reported as one of the most important risk factors for the adverse outcomes of COVID-19 [65, 66]. Studies have shown that diabetics are at higher risk for respiratory infections [67] and have higher mortality rates than non-diabetics [68]. But other studies suggest that despite the increased risk of severe complications following diabetes, including Adult Respiratory Distress Syndrome (ARDS) and multi-organ dysfunction in COVID-19 disease, diabetes alone is not associated with an increased risk of respiratory infections [69]. There are some theories can reveal diabetic patients are susceptible for COVID-19. According to a Mendelian randomization analysis which showed the diseases, traits and blood proteins that may causally affect ACE2 expression in the lung, diabetes mellitus has the most causal effect on the ACE2 expression. The probable hypothesis is that, diabetes not only can increase the chance of worst outcome in patients, but also can empower the risk of COVID-19 infection [70]. Chen et al. [71] stated that diabetes has adverse effect on viral clearance as a gold standard of the recovery of COVID-19 patients. Therefore, diabetic patients will have poor prognosis during infection.

\section{- Pathophysiological link between diabetes and COVID- 19}

Since the initial outbreak of COVID-19 in China, due to the poor prognosis of this respiratory disease in diabetic patients, much attention has been focused on diabetics. Diabetes is one of the most common diseases in the world with an increasing number of patients in recent decades [72]. The global prevalence of diabetes is currently over 382 million people and it estimated to rise to 592 million by 2035 [73, 74]. Diabetes is one of the foremost important risk factors for cardiovascular disorder [75].

Among the comorbidities associated with COVID-19 patients, the prevalence of diabetes was 17.4 [76]. Due to the global prevalence of diabetes, and its extensive effects on mortality and morbidity, special considerations needs to be made for COVID-19 infection in diabetic patients during the COVID-19 pandemic which affects all dimensions of health care. Reasons for a poor prognosis of COVID-19 infection in diabetic patients are multifactorial.

ACE2 is expressed widely in various organs, including the endocrine part of pancreas [77]. Inflammatory stress and cytokine storm during COVID-19 disease, upregulate ACE2 expression in both mRNA and protein in pancreatic beta cells [78]. SARS-CoV-2 could destroy pancreas islet cells by binding ACE2 receptor [79]. Affecting islet cells by SARS-CoV-2 leads to deteriorating the control of blood glucose level. High blood glucose in patients may decrease immune response to SARS-CoV-2 and inhibit neutrophil chemotaxis, phagocytosis, and intracellular killing, resulting 
Table 1 Hypertensive Treatment and COVID-19 Patient Outcomes: various articles on the effect of different hypertensive drugs on the outcome of COVID-19 are shown

\begin{tabular}{|c|c|c|c|c|c|c|}
\hline $\begin{array}{l}\text { Author } \\
\text { (publication date) }\end{array}$ & country & $\begin{array}{l}\mathrm{N} \\
(\mathrm{HTN})^{\mathrm{a}}\end{array}$ & Type of study & Drugs for HTN & Outcome & Endpoints \\
\hline $\begin{array}{l}\text { Yang et al. [56] } \\
\text { March } 2 \text { 2020(56) }\end{array}$ & China & 112(92) & Retrospective cohort & ACEI/ARB & Neutral & $\begin{array}{l}\text { No effect on morbidity } \\
\text { mortality }\end{array}$ \\
\hline $\begin{array}{l}\text { Zhang et al. [57] } \\
\text { April } 10 \text { 2020(57) }\end{array}$ & China & $476(113)$ & Retrospective cohort & ACEI/ARB & positive & $\begin{array}{l}\text { Increased use of ACEI/ } \\
\text { ARB in moderate vs } \\
\text { severe covid19 patients }\end{array}$ \\
\hline $\begin{array}{l}\text { Zhang et al. [57] } \\
\text { April } 17 \text { 2020(54) }\end{array}$ & China & $1128(1128)$ & Retrospective cohort & ACEI/ARB & positive & $\begin{array}{l}\text { Decreased all-cause } \\
\text { mortality }\end{array}$ \\
\hline $\begin{array}{l}\text { Tadic et al. [58] } \\
\text { May } 12020(58)\end{array}$ & Italy & $6272(3632)$ & $\begin{array}{l}\text { Population case control } \\
\text { study }\end{array}$ & ACEI/ARB & Neutral & $\begin{array}{l}\text { No association between } \\
\text { number of patients and } \\
\text { severity or mortality } \\
\text { rate }\end{array}$ \\
\hline $\begin{array}{l}\text { Caldeira et al. [59] } \\
\text { May } 14 \text { 2020(59) }\end{array}$ & Spain & $1139(617)$ & $\begin{array}{l}\text { Population case control } \\
\text { study }\end{array}$ & ACEI/ARB & Neutral & $\begin{array}{l}\text { No increase in ICU } \\
\text { admission or fatal or } \\
\text { hospitalize cases }\end{array}$ \\
\hline $\begin{array}{l}\text { Solaimanzadeh [60] } \\
\text { May } 12 \text { 2020(60) }\end{array}$ & USA & $65(22)$ & Retrospective cohort & CCB & positive & $\begin{array}{l}\text { associated with sig- } \\
\text { nificantly improved } \\
\text { mortality } \\
\text { and a decreased risk } \\
\text { for intubation and } \\
\text { mechanical ventila- } \\
\text { tion in elderly patients } \\
\text { hospitalized }\end{array}$ \\
\hline $\begin{array}{l}\text { Chao Gao et al. [61] } \\
\text { June } 4 \text { 2020(61) }\end{array}$ & China & $2877(850)$ & $\begin{array}{l}\text { retrospective observa- } \\
\text { tional study }\end{array}$ & $\begin{array}{l}\text { No drugs/RAAS/non } \\
\text { RAAS drugs }\end{array}$ & Neutral & $\begin{array}{l}\text { those without antihyper- } \\
\text { tensive } \\
\text { treatment had a signifi- } \\
\text { cantly higher rate of } \\
\text { mortality compared } \\
\text { with those with antihy- } \\
\text { pertensive/no differ- } \\
\text { ence between RAAS } \\
\text { and non RAAS groups }\end{array}$ \\
\hline $\begin{array}{l}\text { Sardu et al. [62] } \\
\text { July } 1,2020(62)\end{array}$ & Italy & $297(152)$ & $\begin{array}{l}\text { Prospective Cohort } \\
\text { Study }\end{array}$ & ACEI/ARB/CCB & Neutral & $\begin{array}{l}\text { Anti-hypertensive drugs } \\
\text { didnt affect the prog- } \\
\text { nosis in patients with } \\
\text { COVID-19 }\end{array}$ \\
\hline $\begin{array}{l}\text { Khawaja et al. [63] } \\
(2020)(63)\end{array}$ & UK & $406,793(135,604)$ & $\begin{array}{l}\text { Prospective Cohort } \\
\text { Study }\end{array}$ & $\begin{array}{l}\text { ACEI, ARB, CCB, } \\
\text { b-blockers, diuretics }\end{array}$ & NEGATIVE & $\begin{array}{l}\text { Hospitalization } \\
\text { with COVID-19 } \\
\text { INCREASE SIGNIFI- } \\
\text { CANTLY with number } \\
\text { of antihypertensive } \\
\text { drug used }\end{array}$ \\
\hline $\begin{array}{l}\text { Liabeuf et al. [64] } \\
\text { 2020(64) }\end{array}$ & France & $268(152)$ & Cohort Study & ACEI, ARB, diuretics & NEGATIVE & $\begin{array}{l}\text { ICU admission, death } \\
\text { increase with use of } \\
\text { RASI compared with } \\
\text { other antihypertensive } \\
\text { drugs and no drugs }\end{array}$ \\
\hline
\end{tabular}

in more severe and prolonged disease [80, 81]. Also, Yang et al. study showed that the binding of SARS-CoV to its receptor on endocrine part of pancreas leads to an acute insulin dependent diabetes mellitus [79]. Another reason for hyperglycemia in COVID-19 patients is insulin resistance due to activated immune system [82]. Thus both impaired insulin secretion and insulin resistance together cause diabetic ketoacidosis (DKA) [83].

\section{- Vicious cycle between COVID-19 and diabetes}

Because of the chronic state of low grade inflammation due to the activation of pro inflammatory mediators and the excessive visceral adipose tissue, diabetic patients have a delay in the activation of Th1 cell-mediated immunity and a late hyperinflammatory response [84]. In a clinical study, which analyzed diabetes in a mouse model of 
MERS-CoV infection, Kulcsar et al. [85] detected that level of inflammatory monocyte/macrophages, CD $4+\mathrm{T}$ cells, TNFa, IL6, IL12b and Arg1 expression are lower in diabetic mice but they have higher levels of IL17a expression. Thus, they believed this dysregulated immune response could be the result of more severe and prolonged lung injury.

Based on Chen et al. meta-analysis patients with severe COVID-19 disease had higher blood glucose level than mild group but $\mathrm{HbA} 1 \mathrm{c}$ did not differ significantly between groups [71].

Zhang et al. in a retrospective cohort study concluded that the fatality of COVID-19 in diabetic patients is associated with the fasting blood glucose [54]; on the other side, new studies on SARS-CoV-2 patients revealed that the inflammatory storm, also known as cytokine release syndrome (CRS), in diabetic patients, leads to rapid deterioration of COVID19. In the first published biochemical features of patients with diabetes, Guo et al. [68] found that serum levels of inflammation-related biomarkers such as IL-6, C-reactive protein, serum ferritin and coagulation index, D-dimer, were significantly higher in diabetic patients compared to those without diabetes.

\section{- Impact of COVID-19 on diabetes management}

Lifestyle changes such as staying at home, social distance and reduction of outdoor activities through the COVID-19 pandemic may result in developing diabetes in susceptible population [86]. Also, these sedentary behaviors may potentially increase the risk of poorer health outcomes in known diabetic patients. Based on World Health Organization (WHO) study on 155 countries, $49 \%$ of diabetic patients disrupted their follow-up care for treatment or their specific complications [87]. In a study on diabetic patients hospitalized for COVID-19 in 53 French centers, authors revealed that BMI, microvascular (including severe diabetic retinopathy, diabetic kidney disease and history of diabetic foot ulcer) and macrovascular complications (including ischemic heart disease, cerebrovascular disease and peripheral artery disease) were associated with the risk of tracheal intubation for mechanical ventilation and/or death within 7 days of admission [88].

Another complication of COVID-19 infection in diabetic patients is thrombotic microangiopathy [89]. Diabetic patients based on their glycemic control, duration of disease and other metabolic conditions have different degrees of endothelial dysfunction [90, 91]. Also, COVID-19 infection itself promote the process of endotheliitis in multiple organs as a direct consequence of viral involvement [92]. Super imposed thrombotic microangiopathy to their endothelial dysfunction and SARS-CoV-2 induced endotheliitis cause serious disease, including renal and neurological disease $[89,93]$.

Because of hyperglycemia effect on Covid-19 patient's treatment and prognosis, managing hyperglycemia is one of the most important steps in patients care. For critically ill patients insulin is a first choice. The benefits of insulin including toll-like receptors (TLRs) suppression, reduction of proinflammatory nuclear transcription factor $\mathrm{kB}$ (NF$\mathrm{kB})$ activation and modulation of inflammatory mediators could improve the prognosis of COVID-19 patients [94-96]. Among different cytokines which increase in CRS, IL6 may play a major role in COVID-19 patients and IL6 blockade could be beneficial to manage COVID19-induced CRS in some diabetic patients [97, 98]. Studies have shown that pioglitazone a drug from the family of thiazolidinediones, a common treatment for insulin resistance, has anti-inflammatory effects and significantly can reduce IL6 and TNF-a [99, 100]. The efficacy of Tocilizumab as a treatment for moderate to severe COVID19 , which binds to the IL-6 receptor, could be affected in diabetic patients with hyperglycemia [101, 102]. Patients should follow the instructions to drink adequate amount of fluids and do aerobic activities while staying in quarantine. It is also important to take enough proteins in their diet and avoid smoking because it could exacerbate the corona virus infection. Patients with diabetes also tend to reduce their meetings with their doctor to avoid exposure to COVID-19 but this could lead to the mismanagement of their disease and uncontrolled hyper or hypoglycemia so the health care system need to develop new policies for telehealth services to provide support and care to diabetic patients during this pandemic safely [103].

\section{- Impact of Diabetes treatment on COVID-19 outcome}

Pharmacological treatment of diabetic patients with COVID-19 disease is associated with considerations. Pharmacological treatments may need to be changed based on the severity of the disease and the likelihood of complications. On the other hand, studies show that some of these classes of antidiabetic drugs may affect the severity or course of COVID-19 disease. In the Fig. 2 we summarized effect of some antidiabetic drugs like Metformin and DPP4 inhibitors on COVID-19 disease which their role is also elaborated in details in the article.

\section{- Metformin:}

In recent studies some mechanisms of action of metformin on COVID-19 was challengingly discussed. The main mechanism of metformin to effect on glucose is the phosphorylation of AMP-activated protein kinase (AMPK) in hepatocytes [104]. AMP activation cause 


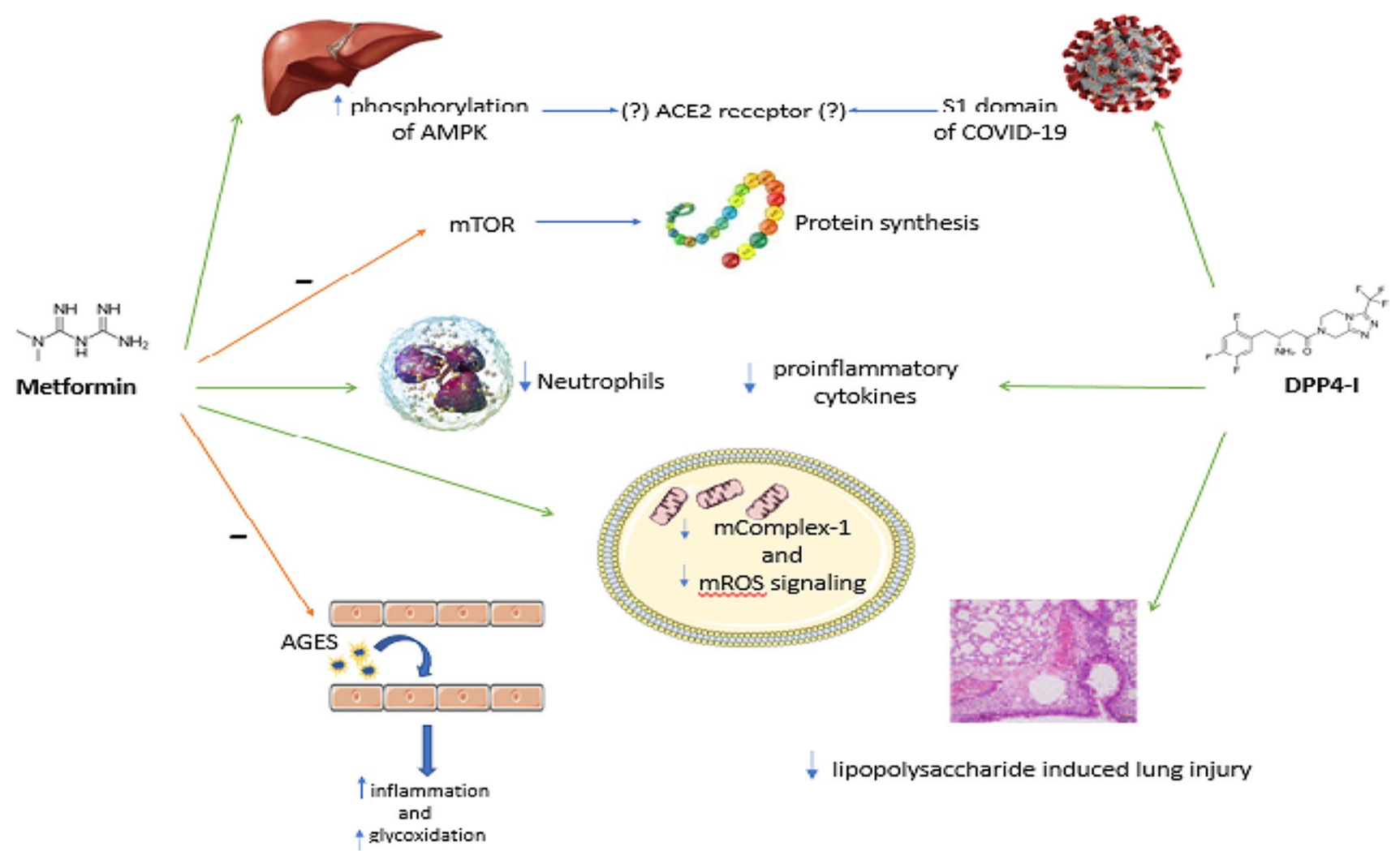

Fig. 2 The relation between antidiabetic drugs such as DDP-4 (Dipeptidyl peptidase 4 Inhibitor) and metformin and COVID-19 infection in a quick review.ACE2 = Angiotensin-converting enzyme

the phosphorylation of ACE2 and this, theoretically can change ACE2 receptor and can potentially reduce the risk of COVID-19 [105, 106]. On the other hand, some authors have suggested that metformin increases ACE2 expression and availability in respiratory tract [107].

Among this conflicting data Pal et al. [108] states there is no interaction between ACE2 and metformin and there is no concern to continue metformin.

Metformin is a medication that is commonly prescribed for all type 2 diabetic patients except those with contraindications. It is especially used in obese patients with diabetes mellitus type 2 because the prevalence of obesity and overweight is high in type 2 diabetic patients and obesity itself is a risk factor of poor prognosis in COVID-19 patients [109, 110].

Based on Luo et al. retrospective analysis, patients with diabetes who receiving metformin showed decreased mortality rate compared to diabetics not receiving metformin [111]. Beside antidiabetic features of metformin, it has various effects including cardiorenal protection, anti-inflammatory effects, cell protection and cancer prevention [112-114]. Also metformin was used as an anti-flu drug to treat influenza [115].
2, $\mathrm{AMPK}=$ adenosine monophosphate-activated protein kinase, $\mathrm{mTOR}=\mathrm{a}$ kinase that in humans is encoded by the MTOR gene, AGES $=$ Advanced glycation end products

One mechanism of the anti-inflammatory effect induced by metformin is the inhibition of advanced glycation end products (AGEs) formation, which enhance inflammation and glycoxidation [116].

Metformin also subside hyperactivation of immune system in many ways including the inhibition of mTOR pathway [117], reduction in neutrophils [118], inhibition of mitochondrial complex 1 and suppression of mitochondrial reactive oxygen species (ROS) signalling [119]. Therefore metformin could reduce insulin resistance. Also, Bramante et al. claimed that metformin has protective effect through the reduction of tumor necrosis factor (TNF) alpha more in female than male. Based on their study, mortality reduction of metformin was significantly observed only in female [120].

Another mechanism of metformin is the damage of viral endocytic cycle by affecting the endosomal $\mathrm{Na}^{+} / \mathrm{H}^{+}$ exchanger, thereby increasing cellular $\mathrm{pH}$ [121].

On the other hand, metformin has some side effects such as lactic acidosis and some contraindications including chronic kidney disease and liver failure which raised concerns about using this beneficial drug for hospitalized patients. Actually, metformin alone is not the reason of lactic acidosis. Patient condition such as organ failure, 
tissue hypoxia, liver and kidney disease facilitate anaerobic glycolysis process $[122,123]$.

Gastrointestinal side effects of metformin including nausea, vomiting, diarrhea, flatulence indigestion, abdominal discomfort and dyspepsia which usually resolve after some days of starting treatment [124]. But it should be distinguished from gastrointestinal symptoms of COVID-19.

\section{- Dipeptidyl peptidase 4 Inhibitor (DPP4 inhibitors)}

Human dipeptidyl peptidase 4 (DPP4 inhibitors), a serine ectopeptidase that is commonly known as cluster of differentiation (CD26) is a functional receptor for MERS-Co-V spike protein $[125,126]$. DPP4 inhibitors also has a soluble form (DPP4 inhibitors) in the circulation [127]. DPP4 inhibitors enzyme beside its effects on glucose and insulin metabolism by inactivating and cleavage incretins such as glucagon like peptide1 (GLP-1), has an important role in activation and proliferation of T cells [128, 129]. DPP4 inhibitors cleavage proline- or alanine-containing peptides including growth factors, chemokines, cytokines, neuropeptides, hormones and vasoactive peptides in many organs including lung, kidney, liver and gastrointestinal tract [130, 131]. Most DPP4 inhibitors such as sitagliptin and linagliptin are competitive with substrate, while vildagliptin and saxagliptin act as pseudo-substrates [132, 133]. Between DPP4 inhibitors, sitagliptin has the shorter distance from one of predicted binding site of SARS-CoV-2 [134, 135]. A meta-analysis found that DPP4 inhibitors which block the enzymatic activity of DPP4 inhibitors do not increase the overall risk of respiratory tract infections [136].

Iacobellis claimed that DPP4 inhibitors, might decrease the risk of severity and complications COVID-19 patients with diabetes [128]. Kawasaki et al. studied sitagliptin effects on lipopolysaccharide induced lung injury in mice [137]. They found sitagliptin by inhibiting proinflammatory cytokines including IL- $1 \beta$, TNF $\alpha$, and IL- 6 could alleviated histological findings of lung injury.

Recent study of Vankadari et al. showed that DPP4 inhibitors may interact with the S1 domain of the viral spike glycoprotein [134]. But based on Tai et al. study, receptor-binding domain (RBD) of Covid-19 binds to human ACE2-expressing $293 \mathrm{~T}$ cells not to human DPP4 inhibitors-expressing 293 T cells [138]. By Pitocco et al. opinion, because of not exclusive role of DPP4 inhibitors binding in tropism of the Coronavirus family, DPP4 inhibitors inhibition is not acceptable treatment for Covid-19[139].

\section{- Glucagon-like peptide-1 (GLP-1) receptor agonists}

GLP-1 receptor agonists such as liraglutide are anti diabetic drug which have anti-inflammatory effects and improve endothelial dysfunction [140, 141]. Reduction of cytokine concentration and pulmonary inflammation in respiratory disease by GLP-1 receptor agonists, could be promising that these agents are beneficial for COVID-19 patients [142-144].

\section{- Thiazolidinediones}

Thiazolidinediones such as pioglitazone are other anti diabetic agent which decrease insulin resistance in peripheral tissues due to their agonistic effect on peroxisome proliferator-activated receptor g1 (PPARg1) and PPARg2 [145]. Other pioglitazone benefits including reduce monocyte gene and protein expression of cytokines, reduction of lung inflammation by controlling adipose inflammation and the reduction of pulmonary fibrosis brings the idea of adding this class of anti-diabetic agents to the list of COVID-19 drugs [146-148].

\section{- Sodium-glucose cotransporter type-2 (SGLT2) inhibi- tors}

Studies showed that sodium-glucose cotransporter type-2 (SGLT2) inhibitors such as dapagliflozin has antiinflammatory effects on the kidney, cardiovascular system and pancreas and it supposed to be helpful for pulmonary involvement of COVID-19 patients [149, 150]. Although a study on diabetic mice showed that dapagliflozin could reduce respiratory infection, because of the risk of euglycaemic ketoacidosis UK guidelines not recommended to use SGLT2 inhibitors [151, 152].

\section{- Diabetes and COVID-19 in brief}

To summarize the available data, diabetes is one of the most important and common comorbidities of Covid-19 disease. COVID-19 is a great health issue which the entire world encountered with it and have an effect on everyday lives of people worldwide. Cardio metabolic disease such as diabetes could be affected by this matter and also could change the process of dealing with this infection and got more serious form of it.

In this article we reviewed different studies evaluate the effect of COVID-19 on diabetes and also the effect of diabetes on severity and management of COVID-19 infection and acute respiratory infection caused by it.Diabetes could alter immune system and weakened the immune response against COVID-19 like other infections such as influenza and pneumonia [67].

And according to various studies, the prevalence and mortality of this contagious infection is higher in diabetic patients. SARS-CoV-2 binding to the endocrine part of pancreas, as an expression site of ACE2, and insulin resistance due to hyper activated immune system cause poor control of glucose level in diabetic patients. Immune system responses 
such as phagocytosis, and intracellular killing diminished during hyperglycemic state. Thus, diabetic patients are more suspicious for poorer prognosis between patients with COVID-19 [77, 78, 84, 85]. The antidiabetic drugs are the other subjects which have been studied repeatedly nowadays and most studies suggest to continue the use of oral agents during this pandemic and also after infection with coronavirus but in critical patients similar to other diseases it has been suggested to use insulin to have better control over the blood sugar of these patients and also to improve their nutritional status and also the overall outcome of the disease [83, 153].

The last matter addressed in the present research is the management of diabetes during this pandemic. Studies suggest that diabetic patients should follow their antidiabetic drugs as prescribed, have routine aerobic activities, control their glycemic indexes in their diet and check their blood sugar to make sure their diabetes is under control and should stay in touch with their physicians by telephone or over the internet to help them be safe and healthy during the pandemic [103].

\section{- Introduction to COVID-19 and Dyslipidemia}

Dyslipidemia characterized as elevated low-density lipoprotein (LDL) cholesterol levels, or low levels of highdensity lipoprotein (HDL) cholesterol, could be the main risk factor for coronary heart disease (CHD) and stroke. [154] Dyslipidemia is a common disease and according to the US national health and nutrition examination survey conducted from 1999 to $2000,25 \%$ of adults had total cholesterol greater than $239.4 \mathrm{mg}$ per dL or were taking lipid lowering medication [155].

We believe that hyperlipidemia is a potential risk factor for deteriorating COVID-19 patients because obesity and underlying medical conditions such as coronary heart disease and metabolic syndrome are closely related to patients with poor prognosis $[36,156,157]$. Based on a meta-analysis by Hariyanto et al. dyslipidemia is an exacerbation factor in the outcome of COVID-19 patients [158].

Cholesterol is the major neutral lipid of pulmonary surfactant [159]. Thus hypercholesterolemia can dysregulate the protective features of surfactant in alveolar spaces [160]. In other hand, cholesterol is a major structural component of immune cell membranes, elevated level of cholesterol can affect pulmonary immune responses; therefore it can enhance pulmonary inflammation response [161, 162].

\section{- Pathophysiological link between Dyslipidemia and COVID-19}

\section{- Low-density lipoprotein (LDL)}

SARS-CoV needs oligomeric status of N-terminal fusion peptide to enter into host cells and recent studies showed cholesterol can facilitate this process [163]. Patients with dyslipidemia have high levels of low-density lipoprotein (LDL). LDL accumulation in macrophages in atherosclerotic plaques and other immune cells, promotes inflammatory responses including augmentation of Toll-like receptor (TLR) signaling, inflammasome activation and the secretion of the pro-inflammatory cytokines such as IL-1B and IL-18 [162]. Cytokine storm in COVID-19 which means the presence of high levels of pro-inflammatory cytokines is associated with severe outcomes [164]. On the other hand, studies have shown that plasma level LDL may be associated with the prognosis of COVID-19 patients. Based on a large retrospective analysis in Wuhan, patients with mild symptoms had hypolipidemia and patients with severe symptoms had more reduced level of LDL and TC [165]. HDL only reduced in critically ill patients but not in mildly infected patients with COVID-19 [165]. Multiple reasons including liver damage and increased metabolism of cholesterol due to hyper inflammation and cytokine storm could explain reduction of LDL level in COVID-19 patients $[165,166]$. Due to liver function damage, synthesis of LDL could be reduced and serum liver enzymes include ALT, AST and ALKP will increase. But fewer than $50 \%$ of patients had moderate increase of liver enzymes that this show minor effect of virus on patients' liver [165, 167]. Also SARS-CoV-2 could inhibit the activity of many proteins involved in cholesterol metabolism [168, 169]. Also increased vascular permeability through hyper inflammation state can cause LDL leakage. In another theory, exudative fluid in patients' lung due to increased vascular permeability has high level of LDL $[170,171]$. Also the degeneration of LDL are increased in COVID-19 patients because of enhanced free radicals from infected host cells [41].

In patients with dyslipidemia, lipotoxicity through accumulation of LDL will cause endothelial dysfunction which activates prothrombotic cascade and eventually leads to vascular thrombosis and cardiovascular complications [172, 173]. Changes in lipid metabolism are an early step in atherogenesis and can cause vessel injury through coagulopathy and endothelial dysfunction $[174,175]$. Thus vasculopathy, the independent risk factor promoting disease severity, is related to cholesterol changes in COVID-19 patients [176]. Also in COVID-19 patients, this endothelial dysfunction has other important role because of ACE2 receptor expression, the receptor for SARS-CoV-2, occur in endothelial cells [177].

\section{- High-density lipoprotein (HDL)}

Patients with dyslipidemia have low levels of highdensity lipoprotein (HDL). HDL-c has potential protective properties in variety of diseases such as cardiovascular disease and viral pneumonia [178]. HDL has ant oxidative, 
anti-inflammatory, ant apoptotic, antithrombotic, anti-infective, and vasoprotective effects [179]. A case-controlled study by Deniz et al. found that serum HDL-c levels are lower in patients with community-acquired pneumonia (CAP) and serum total cholesterol/HDL-c ratios might increase proportionally with radiological extent of the disease in CAP patients [180]. HDL plays a major role in the regulation of innate immune response which working on the first lines of body defense mechanism against COVID-19 infection [181].

In a cross-sectional study on 143 patients with confirmed COVID-19, meaningful decrease of HDL-c was found in severe/critical patients contrast mild/moderate patients [182]. HDL negatively regulates T-cell activation and the expression of inflammatory mediators in macrophages by interaction with ABCA1 or ABCG1 [183, 184]. In another retrospective study conducted on 114 COVID-19 patients and 80 healthy controls, patients had significantly decreased serum total cholesterol, HDL-c and LDL-c but there was no difference in serum level of triglyceride between two groups. And between these lipid changes, only HDL-c is associated with the severity of COVID-19 infection between patients [36]. Decreased serum HDL level could be explained by affinity of SARS-CoV-2 spike protein to attach HDL; thus antagonists of HDL receptor could be used as a potential anti-viral treatment [185]. In another theory, massive suppression of metabolism in COVID-19 patients causes dysregulation of apolipoproteins (Apo) like Apo A1 and Apo E [186]. Also, decreased serum level of lecithin cholesterol acyltransferase (LCAT) due to inflammation could change HDL functions [187]. Another mechanism for HDL dysfunction is the inactivation of paraoxinase 1 (PON1), an antioxidant enzyme of HDL, in inflammatory condition [188]. Through such mechanism, the reduced level of HDL could be explained.

Furthermore studies have shown that HDL-c concentration is associated with other markers meaningfully. $\mathrm{Hu}$ et al. [36] found HDL was negatively correlated with CRP $(r=0.396, P<0.001)$ and positively correlated with lymphocytes $(r=0.396, P<0.001)$. Studies on death cases in Wuhan showed that elevated CRP as well as declined lymphocytes can be used as indicators for disease deterioration [189].

\section{- Apolipoproteins (APOs):}

ApoB, the major apolipoprotein of LDL, are oxidized during inflammation. Also anti-inflammatory effects of HDL are diminished during inflammation by decrease of HDL associated Apos and increase of serum amyloid protein A (SAA) [190]. In fact, inflammation may change hepatic gene expression of apolipoproteins and increase binding of SAA which apoA1 levels [191]. In this case, recent studies declared serum level of SAA as a factor for prognosis of COVID-19 patients [57]. HDL associated lipoproteins such as ApoA1 and ApoM have potential effect on lipid rafts that are enriched in Immune cell receptors such as toll like receptor and T cell receptors [192, 193].

Furthermore ApoE function, as a component of HDL lipoproteins which expressed in lung macrophages and alveolar epithelial cells, could be affected during SARS-CoV-2 infection [194]. As we know IL6 is a major cytokine elevated during the cytokine storm of COVID-19 [195]. In vivo study on mice showed that ApoE-/- animals are more susceptible to acute lung injury during the elevated level of oxLDL due to IL6 induced mechanisms [196]. ApoE4 genotype also was reported as a factor to predict COVID-19 severity. Based on analysis, ApoE4/E4 homozygotes are more suspicious for positive COVID-19 test [194].

Although hypocholesterolemia including decreased level of LDL, HDL and TC have been reported in many advanced diseases, but it can be understood from studies that LDL and HDL level act as markers which could predict poor outcomes in COVID-19 patients [197, 198].

\section{- Impact of lipid-lowering drugs on COVID-19outcome}

Actually until now there is no strong evidence on the use of statins in COVID-19 patients. Statins are known for their lipid-lowering, anti-thrombotic, antioxidant and anti-inflammatory benefits; hence, they were suggested to be used in COVID-19 patients [199, 200]. It have been mentioned that COVID-19 disease in patients already using statins, is milder among home care setting [201]. Also Choi et al. in an umbrella review showed that the mortality rate of COVID-19 patients within 28 days was $5.2 \%$ and $9.4 \%$ in the statin and non-statin groups [202]. Statins lessen cholesterol synthesis by restricting the activity of HMG-CoA reductase.[203]Statins improve endothelial function which plays a major role in pathogenesis of COVID-19 [204-206]. Statins also inhibit the synthesis of other biologically active sterols, oxysterols that have multiple immunomodulatory roles, key isoprenoid intermediates and 25-hydroxycholesterol that involved in the type I interferon antiviral response [207-209].

Based on Zhang et al. study on 13,981 COVID-19 patients, statin therapy significantly reduced the severity and mortality of COVID-19 [210]. Similar to HCV, SARSCoV-2 is a lipid rich enveloped, positive-strand RNA virus. Based on previous studies on hepatitis $\mathrm{C}$ virus (HCV) which showed HCV replication is related with lipid metabolism, fluvastatin administration for chronic $\mathrm{HCV}$ patients may reduce virus reproduction rate and increase virus clearance from the blood [211-213]. SARS-CoV-2 has four main structural proteins including spike (S), envelope (E), membrane $(\mathrm{M})$, and nucleocapsid $(\mathrm{N})$ proteins [214]. The virus 
attach to ACE2 receptor which expressed on lipid rafts of lower respiratory tract cells by S protein [215]. It has been proved that atorvastatin upregulate the expression of ACE2 and high level of ACE2 could facilitate possibility of SARSCoV-2 infection [216, 217]. Also, Lipid rafts play an important role for some certain viruses include SARS-CoV-2 to enter host cells by interaction between S protein and ACE2 receptor [218, 219]. Lipid rafts are discrete lipid domains of the plasma membrane that enriched with cholesterol, glycosphingolipids, and glycosyl-phosphatidylinositol which contain ACE2 receptor [220, 221]. The location of ACE2 on lipid rafts is not clearly understood. Also cholesterol control post-binding processes of virus infection by impressing viral mRNA synthesis in host cells [218]. An important cause of COVID-19 patients' deterioration is ARDS. Statin treatment recommendations for patients with sepsis-associated ARDS and ventilator associated pneumonia (VAP) are conflicting. An observational cohort study showed that statin therapy in patients with sepsis-associated ARDS will improve their outcomes and reduce their mortality rate [222]. Another study stated that pravastatin administration may significantly increase probability of being free from ventilator and reduce patients' mortality rate [223]. On the other hand, some other randomized clinical trials showed that there is no difference between statin therapy and placebo in VAP and sepsis-associated ARDS outcomes [224, 225]. One reason for this conflicting data is subgroup of ARDS and differential response to statin. A randomized controlled trial analysis showed that Simvastatin treatment will significantly improve 28-day survival of hyper inflammatory sub phenotypes rather than hypo inflammatory sub phenotypes; but by rosuvastatin treatment, there was no difference between hyper inflammatory and placebo groups [226, 227]. A recent molecular study in silico showed that statins could block virus entry into cells by inhibition of the main proteinase of SARS-CoV-2 [228]. In this study which compared binding energy of several statins, showed that rosuvastatin, lovastatin, fluvastatin and especially pitavastatin could inhibit main protease (Mpro) of SARS-CoV-2 [228]. However Zho et al. failed to report this interaction [229].

Cellular proliferation require cholesterol, an essential component of cell membranes and the responsible biosynthetic pathway for new cholesterol synthesis is also the source of isoprenoid intermediates used for the prenylation of a large number of intracellular signaling proteins [208]. Statins inhibit protein prenylation by the reduction of isoprenoid intermediates [230]. By this way they could inhibit SARS-CoV-2 infectivity.

By reduce synthesis of 25-hydroxycholesterol, statins could limit the switching of human $\mathrm{CD} 4^{+} \mathrm{T}$ cells from production of the antiviral/pro-inflammatory cytokine IFNgamma to the immunoregulatory IL-10 [231]. Thus statins could enhance the antiviral capability of $\mathrm{CD}^{+} \mathrm{T}$ cells [232].
Other mechanisms of statins to combat pathology of SARS-CoV-2 include endothelial dysfunction and endotheliitis in several organs, stabilizing the endothelial leakage, limiting leukocyte transmigration and increasing local nitric oxide [208, 233]. Another reason for use of statin in COVID19 patients is drugs induced hyperlipidemia that caused by protease inhibitor-based antiretroviral and immunosuppressive drugs are used to treat patients [234, 235]. Finally, in statin treatment for COVID-19 patients, we should notice drug interactions, side effects and contraindications. For instance statins have interaction with some antiretroviral drugs and macrolides [236]. On the other hand myalgia in patients could be one of the COVID-19 symptoms or a side effect of statin. Another lipid-lowering drug is fibrates, which its potential antiviral effects for influenza have been proved [237]. In vitro study on mice infected with influenza virus, Alleva et al. showed that fibrates could increase survival of infected mice [237]. Takano et al. claimed that U18666A, cholesterol synthesis and transport inhibitor, shows antiviral effect against type I feline CoV, but not type II FCoV [238]. Furthermore, an in-depth multi-organ proteomic analysis of COVID-19 patient autopsy samples showed that Niemann-Pick C1 (NPC1) was significantly upregulated in most organs, including the lung, spleen, and heart which might be a potential drug target for COVID-19 treatment [239]. A recent in vitro studies showed scavenger receptor class B type 1 (SR-B1), which facilitate the uptake of cholesteryl esters from HDL in the liver, might be a potential target for COVID-19 drugs and blockade of SR-BI inhibited SARS-CoV-2 infectivity in an in vitro study [240, 241].

Cepharanthine, a Japanese natural drug, was announced by FDA as a potent inhibitor of virus-cell attachment [242]. This drug that approved for managing radiation-induced leukopenia [243], alopecia areata [244], alopecia pityrodes [245], idiopathic thrombocytopenic purpura [246], has antiinflammatory, ant oxidative, immunomodulating, antiparasitic, and antiviral effects.

Cepharanthine effects several aspects of cell metabolism including cholesterol trafficking [244].

\section{- Dyslipidemia and COVID-19 in brief}

Dyslipidemia as an effective factor in the occurrence of myocardial infarction as well as stroke is known as a cardio metabolic risk factors affecting human's health.

In this article we reviewed different studies which evaluated dyslipidemia as a prognostic risk factor in this pandemic of COVID-19 and its role in the course of this acute respiratory infectious disease. Dyslipidemia affects the COVID-19 disease in different due to its different roles, including increasing LDL and lowering HDL, as well as altering in Apo protein levels. Accumulation of LDL in 
dyslipidemia causes vasculopathy which is an independent risk factor in increasing the severity of COVID-19 disease. Also this vasculopathy leads to endothelial damage and the expression of ACE2 receptor in endothelial cells as an entry way for SARSCOV2 into cells [176, 177].

Low level of HDL is a prognostic risk factor of COVID19 disease severity by multiple mechanisms which has been explained in details before. There is controversy of using statins in COVID-19 patients but most studies have supported the use of it in these patients [160, 206, 228, 230, 231], although a number of studies in conflict with this theory have also been reviewed [224, 225, 247]. Recent studies have shown that scavenger receptor classB type1 (SR_B1) which facilitate the uptake of cholesteryl esters from HDL in liver, might be a potential target for COVID-19 drugs but these are still invitro studies [240, 241].

\section{Introduction to COVID-19 and Obesity}

Corona virus, as the latest pandemic in the world, causes severe and acute infections of the respiratory system, but it affects all organs of the body [248]. Obesity as an epidemic of the last century also has different effects on the body systems, especially the immune system, so the impact of obesity on COVID-19 disease seems to be possible. Obesity has reached epidemic levels in the United States and most of the western world. About three fourths of adults older than 20 years old in the US meet the criteria for being diagnosed as overweight or obese $(\mathrm{BMI}=$ weight in kilograms divided by the height in meters squared $\left.\geq 30 \mathrm{~kg} / \mathrm{m}^{2}\right)$. More than $9 \%$ of the US adults are morbid or severe obese (BMI $\geq 40)$. Other countries have also reported an increasing prevalence of obesity $[249,250]$. Obesity mainly affects most of the physiological process and interfere the functions of the system including immune system [251]. As an evidence of this claim, reference is made to the H1N1 influenza A occurred in 2009, in which a significant number of the hospitalized patients and mortality cases were related to obese individuals, and an estimated $151,700-575,400$ total death was reported [252, 253]. Due to this, the higher mortality rate in obese patients with novel COVID-19 infection is predictable. To review the major cause of higher mortality rate in obese patients, we can acknowledge metabolic syndrome and other comorbidities such as HTN and DM which themselves increase the mortality rate significantly and the major role of obesity in impairing the immune system in various way [30, 37, 254-256]. This will be discussed in details in the following.

\section{- Pathophysiological link between obesity and COVID-19 - Definition of obesity}

Obesity can lead to more advanced and severe disease in COVID-19 patients by increasing insulin resistance and over activity of the RAAS system as well as creating an inflammatory background [156]. Body mass index (BMI), which is weight in kilograms split up by height in meters squared, is used to recognize obesity. For adults, a BMI of 25.0 to $29.9 \mathrm{~kg} / \mathrm{m} 2$ is defined as overweight and a BMI of $30 \mathrm{~kg} / \mathrm{m} 2$ or higher is defined as obese [257]. For every 5-unit increase in BMI above $25 \mathrm{~kg} / \mathrm{m} 2$, overall mortality increases by $29 \%$, vascular mortality by $41 \%$, and diabetes-related mortality by $210 \%$ [258]. Patients with obesity are at higher risk of morbidity from dyslipidemia, T2D, hypertension, coronary heart disease, stroke, gallbladder disease, respiratory problems, sleep apnea, osteoarthritis, and some cancers [257]. Obesity prevalence is higher in older adults compared to the young, and its complications, such as hypertension, diabetes and cardiovascular disease, increase with increasing obesity severity and duration [259]. Importantly, a report on 4103 patients with COVID-19 disease in New York City found that the most important clinical features leading to hospital admission were age $>65$ years and obesity itself, more than hypertension, diabetes or cardiovascular disease [260].

\section{- Mechanism of effect of obesity on COVID-19 \\ - Respiratory system}

As previous studies showed, obesity is related with higher risk of many respiratory system diseases like asthma and obstructive sleep apnea syndrome [261]. Compliance of respiration system and expiratory reserve volume are commonly reduced in obese individuals due to their altered respiratory mechanism and chest wall physiology. Deposits of mediastinal and abdominal adipose tissue lead to some changes in their respiration physiology such as reduction in chest wall elastance, limitation in truncal expansion, lowering of respiratory muscles strength and increased airway resistance [262-264]. Overall, these functional and physiological changes predisposed them to hypoventilation- associated pneumonia, pulmonary hypertension, and cardiac stress [265]. Moreover, obese individuals consume more oxygen to retrieve lower P02 due to poor-ventilation of lower zones of lungs and ventilation-perfusion mismatch [266-269]. These could explain why respiratory system of obese patients is vulnerable to viral infection like COVID-19.

\section{- Immune system}

There are multiple mechanisms that make obese individuals' immune system vulnerable to defeat the SARS$\mathrm{CoV} 2$ infection. Excess adipose tissue is responsible for over secration of adipocytes and proinflammatory cytokines and put obese individuals in a proinflammatory state. This state upset the balance between cytokines and leads to an impaired immune response. Tumor necrosis factor (TNF- $\alpha$ ), interleukin-6 (IL-6), and C-reactive protein (CRP) are some 
of these oversecrated cytokines [270, 271]. Moreover, IL-6 oversecration is an COVID-19 severity independent factor [256]. Also, high levels of IL-6 may be associated with the overreaction of complement system in obese patients [272, 273]. This state and especially, IL-6 predispose immune system to an impaired response like cytokine storm and further multiorgan failure which were seen in severe cases of COVID-19 [271, 274, 275].

The proinflammatory state also could lead to a decrease in macrophage activation [276, 277]. Also, obesity associated with the disruption of lymphoid tissue integrity and leukocyte activity impairment [278]. This could result in memory T-cell decrease and malfunction that could contribute to more tissue damage during COVID-19 immune challenge [279] and weak antibody response as reported by influenza's vaccination studies [276].

High levels of Leptin and DPP4 inhibitors (Dipeptidyl peptidase-4) in obese patients are two other potential mechanisms that impair immune system. DPP4 inhibition is one mechanism that could suppress proinflammatory cytokines secretion [280], and also leptin plays a crucial role in B cells' cycle [281], both mechanisms are impaired in obese individuals.

\section{- Other comorbidities in obese patients}

In addition to the association obesity and independent risk factors of COVID-19 severity, such as T2DM and HTN, metabolic disorders related to obesity could increase the risk of cardiovascular events [265]. It is very important to note that in most studies the reason of higher mortality rates in obese people was not only attributable to obesity, but the associations of obesity and hypertension, diabetes mellitus and cardiovascular disorders play a great role in higher death rates in these individuals [282-284]. Vitamin D deficiency is another possible risk factor for developing severe COVID-19 [285]. Vitamin D as an immunomodulator plays an essential role in decreasing the production of proinflammatory cytokines. About $40-80 \%$ of the obese population is vitamin D deficient [286]. Also, obese patients admitted to ICU with malnutrition had a worse prognosis than obese patients without malnutrition [287].

\section{- Severe acute respiratory syndrome coronavirus 2 (SARS-CoV-2) Receptors in obese patients}

Also, one of the potential mechanisms that could explain why obesity should be considered as a risk factor for COVID-19 is the high levels expression of ACE-2 (Angiotensin-Converting Enzyme 2) receptors known as the main SARS-CoV2 binding receptors in adipose tissue [288, 289]. Epicardial and ectopic fat tissues could eases spreading the virus to lung, heart and other organs [279].

\section{- Endothelial dysfunction}

There is evidence of endothelial dysfunction in obesity. Obesity related endothelial dysfunction is caused by several mechanisms like low grade inflammation produced by either perivascular adipose tissue or the vasculature itself. This endothelial dysfunction may lead to subsequent damages to some vital organs which also affects the severity of COVID19 infection in obese patients [290, 291].

\section{- Management of hospitalized obese patients}

Moreover, there are some challenges in managing obese patients: requiring more ICU beds, lack of bariatric beds, difficulty in transportation and positioning, weight limits of CT-scan machines, difficult catheterization and intubation due to fat tissue in larynx [278, 292-294].

\section{- Role of visceral and abdominal adipose tissue}

Abdominal fat, composed from 2 adipose layers: visceral and subcutaneous. Subcutaneous layer links to decreased expiratory reserve volume by reducing excursion of diaphragm excursion [295]. However, visceral abdominal fat is associated with metabolic syndrome [296], and type 2 diabetes mellitus and hypertension as parts of metabolic syndrome are independent risk factors of COVID-19 severity [265]. Moreover, the proinflammatory state in obese individuals could be induced by either abdominal or non-abdominal Visceral adipose tissue [294].

\section{- Studies on the association between obesity and COVID- 19 severity}

In a meta-analysis which studied reporting mortality with COVID-19 in patients with/without obesity, they reviewed 14 studies on this subject. The data has shown that body mass index (BMI) to be significantly associated with the mortality. Patients with BMI $\geq 25$ are extremely more likely demand advance respiratory support and also $\mathrm{BMI} \geq 30$ is a considerable factor for critical illness during COVID-19 [297]. Another study were performed in China on 383 patients reveals that obese patients compared to normal weight patients even after adjusting for potential confounders had a 2.42 fold higher risk of developing severe pneumonia [298]. There are several studies on the need for mechanical ventilation in obese patients including A study of 124 COVID-19 patients admitted in the intensive care unit in a university hospital in Lille, France, which reported a 7.36-fold need for intubation in patients with BMI $>35$ (85.7\% of them) compared to those with BMI $<25 \mathrm{~kg} / \mathrm{m} 2$, independent of other comorbidities. Obesity $(\mathrm{BMI} \geq 30)$ and severe obesity (BMI $\geq 35$ ) were found in $47.6 \%$ and $28.2 \%$ 
of cases [299, 300]. Also, another study on 92 patients with COVID-19-associated pneumonia in Italy demonstrated that obesity is linked to a higher requirement of assisted ventilation (mechanical or non-invasive ventilation) and ICU admission, as two important indicators of disease severity, after adjusting for other variables. This study reported intensive or semi-intensive respiratory unit admission and mortality in $41.3 \%$ and $47.4 \%$ of obese patients. However, in this study, obese patients did not show significantly higher mortality rates [301].

\section{- Recommendations on weight control in COVID-19 era}

According to obesity effects on COVID-19, weight gain prevention is highly recommended during the pandemic. Changing lifestyle plays the most critical role in this prevention. Increase physical activity and exercise at home or outdoor with social distancing are critical ways to prevent weight gain in normal-weight people and also lose weight in overweight or obese individuals. Exercise also could improve the metabolic and immunologic functions of the

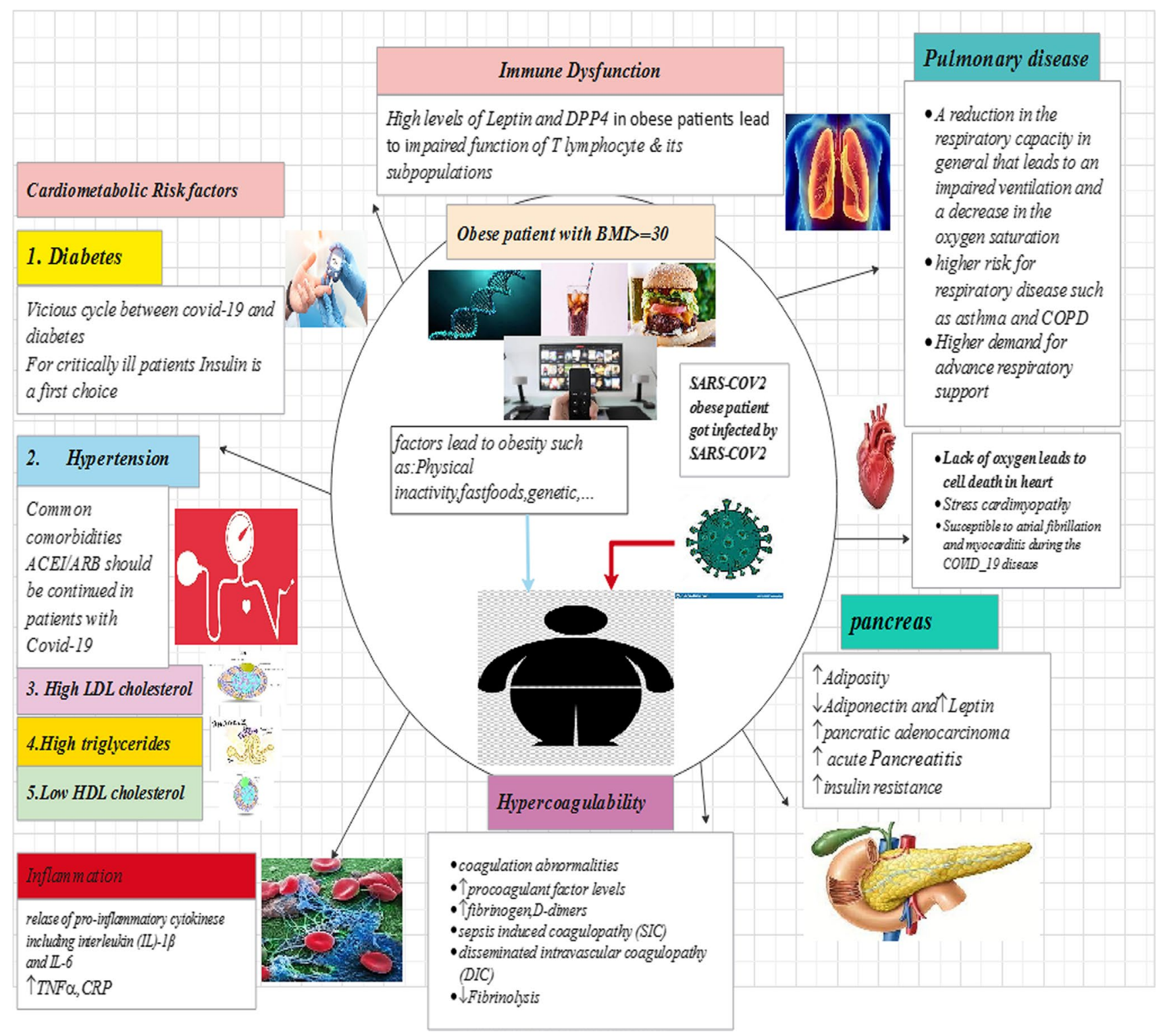

Fig. 3 possible obesity implications and mechanisms in COVID-19 disease. $\mathrm{AF}=$ atrial fibrillation, $\mathrm{COPD}=$ Chronic obstructive pulmonary disease, $\mathrm{HDL}=$ high density lipoprotein, $\mathrm{HFpEF}=$ heart failure with preserved ejection fraction, IL-6=interleukin 6 , $\mathrm{LDL}=$ low-density lipoprotein,DPP4=Dipeptidyl peptidase-4,
SARS-CoV- $2=$ severe acute respiratory syndrome Coronavirus $2, \mathrm{TNF}-\mathrm{a}=$ tumor necrosis factor $\mathrm{a} . \mathrm{CRP}=\mathrm{C}$-reactive protein, $\mathrm{ACE}=$ angiotensin- converting enzyme, $\mathrm{ARB}=$ angiotensin receptor blocker, $\mathrm{BMI}=$ Body mass index,COVID-19 $=$ Coronavirus Disease 2019 
body [302]. Creative methods to do exercise more at home and also, high activity games with children may help to more activity despite limitations. Reduced high-caloric food consumption is another feasible way to lose weight. Increase fresh foods and decrease canned and junk food consumption are notable points that should not be ignored in this era. Moreover, psychological support and treatment or medical interventions to control stress and avoiding emotional eating, and also, sleep regulation could be so useful to reach this purpose.

In addition to these recommendations, obese patients should consider a steady low- caloric diet and approved weight loss drugs (synthetic or herbal drugs under physician observation) to lose weight due to their increased risk of disease [303, 304]. Similarly, obese patients who have diabetes should tightly monitor their glycemic status and adapt their drugs and calorie consumption to these new conditions [300]. As a result, telemedicine could play a crucial role in the close monitoring of obese patients in the COVID-19 era.

\section{- Obesity and COVID-19 in brief}

In conclusion obesity as an epidemic of the last century in conjunction with the coronavirus pandemic can play an important role in changing the course of this infectious disease. As cited acknowledged in the article, obesity can reduce ERV (expiratory reserve volume) and FC (functional capacity) which leads to impaired ventilation [295]. Obesity weakens the immune system by multiple mechanisms. Metabolic syndrome and other comorbidities like DM and HTN will complicate the situation for obese patients tremendously. The ACE2 expression in adipose tissue is higher than that in the lungs, a major target organ by COVID-19 suggesting that adipose tissue May be more susceptible to COVID-19 infection. The obese populations have more adipose tissue and accordingly higher ACE levels. This potential mechanism can increase COVID-19 infection in obese individuals [288]. To sum up, obesity will affect infected patients with COVID-19 in several ways so all the physicians worldwide encourege obese people to better control their diet, their weight and other diseases associated with obesity such as diabetes and HTN during this pandemic era. Figure 3 depicts briefly the mechanisms involved in the potential association between obesity and COVID-19 disease.

\section{Conclusion}

Due to the predominance of individuals with cardio metabolic illnesses, in this pandemic, we decided to review articles on the impact of cardio metabolic risk factors on coronavirus disease 2019 and the viability of coronavirus within the course of cardio metabolic diseases. Various studies revealed the association between the severities of COVID19 infection in individuals with hypertension besides the higher frequency of this infection in these people. Most of the articles looked into in this paper concurred on continuing treatment with ACEI or ARB (as the foremost common antihypertensive drugs) during this pandemic and after getting COVID-19 disease. Diabetes is another cardio metabolic risk factor that in this article is perceived as one of the factors that exacerbated COVID-19 infection, but autonomously was not a factor in increasing the chance of developing the disease. Dyslipidemia is a viable factor within the occurrence of myocardial infarction as well as stroke, and is known as a cardio metabolic risk factor impacting human wellbeing. Dyslipidemia affects the COVID-19 infection in several ways, including the level of HDL as a prognostic risk factor of COVID-19 disease severity by multiple components which has been clarified in detail before. There's a controversy over using statins in COVID-19 infected patients but a plenty of research have supported the usage of these drugs in these patients. Obesity is an epidemic of the last century that in conjunction with the coronavirus pandemic can play an important role in changing the course of this infectious disease. The ACE2 expression in adipose tissue is higher than that in the lungs as a major target organ by COVID-19 implying that adipose tissue may be more vulnerable to COVID-19 infection. In general, due to the high prevalence of cardiometabolic diseases, especially in the population over 60 years old, it seems that these diseases have contributed to the worsening of COVID-19 disease in a recent pandemic, and monitoring these cardiometabolic risk factors can improve the course of COVID-19 infections and could be beneficial generally.

Acknowledgements Implementation of this study was sponsored by Tehran University of Medical Sciences (Endocrinology and Metabolism Research Center).

\section{Declarations}

Conflict of interest Yasaman Sharifi, Moloud Payab, Erfan MohammadiVajari, Seyed Morsal Mosallami Aghili, Farshad Sharifi, Neda Mehrdad, Elham Kashani, Zhaleh Shadman, Bagher Larijani, Mahbube Ebrahimpur declare that they have no conflict of interest.

\section{References}

1. Tu YF, et al. A Review of SARS-CoV-2 and the Ongoing Clinical Trials. Int J Mol Sci. 2020;21(7).

2. Rod JE, Oviedo-Trespalacios O, Cortes-Ramirez J. A briefreview of the risk factors for covid-19 severity. Rev Saude Publica. 2020;54:60.

3. Gaziano TA, et al. Cardiometabolic risk in a population of older adults with multiple co-morbidities in rural south africa: the HAALSI (Health and Aging in Africa: longitudinal studies of INDEPTH communities) study. BMC Public Health. 2017;17(1):206. 
4. Sommerstein R, et al. Coronavirus Disease 2019 (COVID-19): Do Angiotensin-Converting Enzyme Inhibitors/Angiotensin Receptor Blockers Have a Biphasic Effect? J Am Heart Assoc. 2020;9(7):e016509.

5. Letko M, Marzi A, Munster V. Functional assessment of cell entry and receptor usage for SARS-CoV-2 and other lineage B betacoronaviruses. Nat Microbiol. 2020;5(4):562-9.

6. Ferrario CM, et al. Effect of angiotensin-converting enzyme inhibition and angiotensin II receptor blockers on cardiac angiotensinconverting enzyme 2. Circulation. 2005;111(20):2605-10.

7. Esler M, Esler D. Can angiotensin receptor-blocking drugs perhaps be harmful in the COVID-19 pandemic? J Hypertens. 2020;38(5):781-2.

8. Diaz JH, Hypothesis: angiotensin-converting enzyme inhibitors and angiotensin receptor blockers may increase the risk of severe COVID-19. J Travel Med. 2020.

9. Barochiner J, Martínez R. Use of inhibitors of the renin-angiotensin system in hypertensive patients and COVID-19 severity: A systematic review and meta-analysis. J Clin Pharm Ther. 2020;45(6):1244-52.

10. Zhang Jj, et al. Clinical characteristics of 140 patients infected with SARS-CoV-2 in Wuhan, China. Allergy. 2020.

11. $\mathrm{Wu} \mathrm{Z,} \mathrm{McGoogan} \mathrm{JM.} \mathrm{Characteristics} \mathrm{of} \mathrm{and} \mathrm{important} \mathrm{les-}$ sons from the coronavirus disease 2019 (COVID-19) outbreak in China: summary of a report of 72314 cases from the Chinese Center for Disease Control and Prevention. JAMA. 2020;323(13):1239-42.

12. Yang J, et al. Prevalence of comorbidities in the novel Wuhan coronavirus (COVID-19) infection: a systematic review and meta-analysis. International j infect dis. 2020.

13. Li S, et al. Diabetes mellitus and cause-specific mortality: a population-based study. Diabetes Metab J. 2019;43(3):319-41.

14. McDonald $\mathrm{H}$, et al. New estimates of the burden of acute communityacquired infections among older people with diabetes mellitus: a retrospective cohort study using linked electronic health records. Diabet Med. 2014;31(5):606-14.

15. Hussain A, Bhowmik B, do Vale Moreira NC. COVID-19 and diabetes: Knowledge in progress. Diabetes research and clinical practice. 2020 Apr 9:108142.

16. Wang A, Timely blood glucose management for the outbreak of, , et al. novel coronavirus disease (COVID-19) is urgently needed. Diabetes Res Clin Pract. 2019;2020:162.

17. Gordon DJ, Rifkind BM. High-density lipoprotein-the clinical implications of recent studies. N Engl J Med. 1989;321(19):1311-6.

18. Pencina MJ, et al. Predicting the thirty-year risk of cardiovascular disease: the Framingham Heart Study. Circulation. 2009;119(24):3078.

19. Dyslipidemia. Annals of Internal Medicine, 2017. 167(11): p. ITC81-ITC96.

20. van der Stoep M, Korporaal SJ, Van Eck M. High-density lipoprotein as a modulator of platelet and coagulation responses. Cardiovasc Res. 2014;103(3):362-71.

21. Vaisse C, Reiter JF, Berbari NF. Cilia and obesity. Cold Spring Harb Perspect Biol. 2017;9(7):a028217.

22. Hotamisligil GS. Inflammation, metaflammation and immunometabolic disorders. Nature. 2017;542(7640):177-85.

23. Donohoe CL, et al. Emerging concepts linking obesity with the hallmarks of cancer. Trends Endocrinol Metab. 2017;28(1):46-62.

24. Ritter A, et al. Obesity and COVID-19: molecular mechanisms linking both pandemics. Int J Mol Sci. 2020;21(16):5793.

25. Zaki N, Alashwal H, Ibrahim S. Association of hypertension, diabetes, stroke, cancer, kidney disease, and high-cholesterol with COVID-19 disease severity and fatality: a systematic review. Diabetes Metab Syndr. 2020;14(5):1133-42.
26. Roser M, et al. Coronavirus pandemic (COVID-19). Our World in Data. 2020.

27. Control CfD. and Prevention, Novel coronavirus, Wuhan. China. Information for Healthcare Professionals. https://www. cdc.gov/coronavirus/2019-nCoV/hcp/index.html (Accessed on February 14, 2020), 2019.

28. Guan W-J, et al. Comorbidity and its impact on 1590 patients with COVID-19 in China: a nationwide analysis. Eur Respir J. 2020;55(5):2000547.

29. Zekavat $S$, et al. Influence of blood pressure on pneumonia risk: Epidemiological association and Mendelian randomisation in the UK Biobank. 2020.

30. Guan W-J, et al. Clinical Characteristics of Coronavirus Disease 2019 in China. N Engl J Med. 2020;382(18):1708-20.

31. Kearney PM, et al. Worldwide prevalence of hypertension: a systematic review. J Hypertens. 2004;22(1):11-9.

32. Mills KT, Stefanescu A, He J. The global epidemiology of hypertension. Nat Rev Nephrol. 2020;16(4):223-37.

33. HAGHDOUST A, Sadeghirad B, REZAZADEH KM. Epidemiology and heterogeneity of hypertension in Iran: a systematic review. 2008.

34. Shah SJ, Stafford RS. Current trends of hypertension treatment in the United States. Am J Hypertens. 2017;30(10):1008-14.

35. Richardson S, et al. Presenting characteristics, comorbidities, and outcomes among 5700 patients hospitalized with COVID19 in the New York City area. Jama, 2020.

36. Zhou F, et al. Clinical course and risk factors for mortality of adult inpatients with COVID-19 in Wuhan, China: a retrospective cohort study. The lancet. 2020.

37. Grasselli G, et al. Baseline characteristics and outcomes of 1591 patients infected with SARS-CoV-2 admitted to ICUs of the Lombardy Region. Italy Jama. 2020;323(16):1574-81.

38. Xie J, et al. Clinical characteristics of patients who died of coronavirus disease 2019 in China. JAMA Netw Open. 2020;3(4):e205619-e205619.

39. Fryar CD, et al. Hypertension prevalence and control among adults: United States, 2015-2016. 2017.

40. Kulkarni S, Jenner BL, Wilkinson I. COVID-19 and hypertension. Journal of the Renin-Angiotensin-Aldosterone System. 2020 21(2):1470320320927851.

41. Wan Y, et al. Receptor Recognition by the Novel Coronavirus from Wuhan: an Analysis Based on Decade-Long Structural Studies of SARS Coronavirus. J Virol. 2020;94(7):e00127-e220.

42. Shi L, et al. Angiotensin-converting enzymes and drug discovery in cardiovascular diseases. Drug Discovery Today. 2010;15(9-10):332-41.

43. Gheblawi M, et al. Angiotensin-Converting Enzyme 2: SARSCoV-2 Receptor and Regulator of the Renin-Angiotensin System: Celebrating the 20th Anniversary of the Discovery of ACE2. Circ Res. 2020;126(10):1456-74.

44. Chen L, et al. The ACE2 expression in human heart indicates new potential mechanism of heart injury among patients infected with SARS-CoV-2. Cardiovasc Res. 2020;116(6):1097-100.

45. Schulman IH, et al. Altered renal expression of angiotensin II receptors, renin receptor, and ACE-2 precede the development of renal fibrosis in aging rats. Am J Nephrol. 2010;32(3):249-61.

46. Liu W, et al. Detection of Covid-19 in children in early January. 2020 1370-1371.

47. Shang J, et al. Structural basis of receptor recognition by SARSCoV-2. Nature. 2020;581(7807):221-4.

48. Xudong $X$, et al. Age-and gender-related difference of ACE2 expression in rat lung. Life Sci. 2006;78(19):2166-71.

49. Walls AC, Park YJ, Tortorici MA, Wall A, McGuire AT, Veesler D. Structure, function, and antigenicity of the SARS-CoV-2 spike glycoprotein. Cell. 2020 16;181(2):281-92. 
50. Sriram K, Insel PA. Risks of ACE Inhibitor and ARB Usage in COVID-19: Evaluating the Evidence. Clin Pharmacol Ther. 2020;108(2):236-41.

51. Vaduganathan $\mathrm{M}$, et al. Renin-angiotensin-aldosterone system inhibitors in patients with Covid-19. N Engl J Med. 2020;382(17):1653-9.

52. Meng J, et al. Renin-angiotensin system inhibitors improve the clinical outcomes of COVID-19 patients with hypertension. Emerging Microbes \& Infections. 2020;9(1):757-60.

53. Yahyavi A, et al. Angiotensin enzyme inhibitors and angiotensin receptor blockers as protective factors in COVID-19 mortality: a retrospective cohort study. Intern Emerg Med. 2020: p. 1-11.

54. Zhang P, et al. Association of Inpatient Use of Angiotensin-Converting Enzyme Inhibitors and Angiotensin II Receptor Blockers With Mortality Among Patients With Hypertension Hospitalized With COVID19. Circ Res. 2020;126(12):1671-81.

55. de Almeida-Pititto B, et al. Severity and mortality of COVID 19 in patients with diabetes, hypertension and cardiovascular disease: a meta-analysis. Diabetol Metab Syndr. 2020;12:75-75.

56. Yang $\mathrm{G}$, et al. Effects of ARBs and ACEIs on virus infection, inflammatory status and clinical outcomes in COVID-19 patients with hypertension: a single center retrospective study. Hypertension. 2020.

57. Zhang X, et al. ACEI/ARB use and risk of infection or severity or mortality of COVID-19: a systematic review and meta-analysis. Pharmacol Res. 2020 p.104927.

58. Tadic M, et al. COVID-19, hypertension and cardiovascular diseases: Should we change the therapy? Pharmacol Res. 2020: p. 104906.

59. Caldeira D, et al. Angiotensin-converting enzyme inhibitors and angiotensin-receptor blockers and the risk of COVID-19 infection or severe disease: systematic review and meta-analysis. IJC Heart Vasc. 2020;31:100627.

60. Solaimanzadeh I. Nifedipine and Amlodipine Are Associated With Improved Mortality and Decreased Risk for Intubation and Mechanical Ventilation in Elderly Patients Hospitalized for COVID-19. Cureus. 2020;12(5):e8069.

61. Gao C, et al. Association of hypertension and antihypertensive treatment with COVID-19 mortality: a retrospective observational study. Eur Heart J. 2020;41(22):2058-66.

62. Sardu C, et al. Could Anti-Hypertensive Drug Therapy Affect the Clinical Prognosis of Hypertensive Patients With COVID19 Infection? Data From Centers of Southern Italy. J Am Heart Assoc. 2020;9(17):e016948.

63. Khawaja AP, et al. Associations with covid-19 hospitalisation amongst 406,793 adults: the UK Biobank prospective cohort study. medRxiv. 2020.

64. Liabeuf S, et al. Association between renin-angiotensin system inhibitors and COVID-19 complications. European Heart J-Cardiovascular Pharmacotherapy. 2020.

65. Zhou J, Tan J. Diabetes patients with COVID-19 need better blood glucose management in Wuhan. China Metabolism. 2020;107:154216.

66. Yang X, et al. Clinical course and outcomes of critically ill patients with SARS-CoV-2 pneumonia in Wuhan, China: a single-centered, retrospective, observational study. The Lancet Resp Med. 2020.

67. Gupta R, et al. Clinical considerations for patients with diabetes in times of COVID-19 epidemic. Diabetes \& metabolic syndrome. 2020;14(3):211.

68. Guo W, et al. Diabetes is a risk factor for the progression and prognosis of COVID-19. Diabetes/metabolism research and reviews. 2020 36(7):e3319.

69. Fadini G, et al. Prevalence and impact of diabetes among people infected with SARS-CoV-2. J Endocrinol Invest. 2020;1.

70. Rao S, Lau A, So HC. Exploring diseases/traits and blood proteins causally related to expression of ACE2, the putative receptor of
SARS-CoV-2: a Mendelian randomization analysis highlights tentative relevance of diabetes-related traits. Diabetes Care. 2020 1;43(7):1416-26.

71. Chen J, et al. The impact of COVID-19 on blood glucose: A systematic review and meta-analysis. Front endocrinol. 2020;11.

72. Dal Canto E, et al. Diabetes as a cardiovascular risk factor: An overview of global trends of macro and micro vascular complications. European j prevent cardiol. 2019. 26(2_suppl): p. 25-32.

73. Zimmet PZ, et al. Diabetes: a 21st century challenge. Lancet Diabetes Endocrinol. 2014;2(1):56-64.

74. Atlas D. International Diabetes Federation. IDF Diabetes Atlas, 7th edn. Brussels, Belgium: International Diabetes Federation, 2015.

75. Carlsson AC, et al. Association of soluble tumor necrosis factor receptors 1 and 2 with nephropathy, cardiovascular events, and total mortality in type 2 diabetes. Cardiovasc Diabetol. 2016;15:40.

76. Bajgain KT, et al. Prevalence of comorbidities among individuals with COVID-19: A rapid review of current literature. Am $\mathrm{j}$ infect control. 2020.

77. Tikellis C, et al. Improved islet morphology after blockade of the renin-angiotensin system in the ZDF rat. Diabetes. 2004;53(4):989-97.

78. Fignani D, et al. SARS-CoV-2 receptor Angiotensin I-Converting Enzyme type 2 is expressed in human pancreatic islet $\beta$-cells and is upregulated by inflammatory stress. BioRxiv. 2020.

79. Yang J-K, et al. Binding of SARS coronavirus to its receptor damages islets and causes acute diabetes. Acta Diabetol. 2010;47(3):193-9.

80. Insuela D, et al. Neutrophil Function Impairment Is a Host Susceptibility Factor to Bacterial Infection in Diabetes, in Cells of the Immune System. 2019, IntechOpen.

81. Alba-Loureiro T, et al. Neutrophil function and metabolism in individuals with diabetes mellitus. Braz J Med Biol Res. 2007;40(8):1037-44.

82. Šestan M, et al. Virus-induced interferon- $\gamma$ causes insulin resistance in skeletal muscle and derails glycemic control in obesity. Immunity. 2018;49(1):164-177. e6.

83. Bornstein SR, et al. Practical recommendations for the management of diabetes in patients with COVID-19. The lancet Diabetes \& endocrinol. 2020.

84. Hodgson K, et al. Immunological mechanisms contributing to the double burden of diabetes and intracellular bacterial infections. Immunology. 2015;144(2):171-85.

85. Kulcsar KA, et al. Comorbid diabetes results in immune dysregulation and enhanced disease severity following MERS-CoV infection. JCI insight. 2019;4(20).

86. Sathish T, et al. Potential metabolic and inflammatory pathways between COVID-19 and new-onset diabetes. Diabetes \& Metabolism. 2020.

87. COVID W. significantly impacts health services for noncommunicable diseases. 2020. Disponibil pe: www.who.int/news-room/detail/ 01-06-2020-covid-19-significantly-impacts-health-services-fornoncom-municable-diseases.

88. Cariou B, et al. Phenotypic characteristics and prognosis of inpatients with COVID-19 and diabetes: the CORONADO study. Diabetologia. 2020;1-16.

89. Muniangi-Muhitu H, et al. Covid-19 and Diabetes: A Complex Bidirectional Relationship. Front Endocrinol. 2020;11:758.

90. Hadi HA, Al Suwaidi J. Endothelial dysfunction in diabetes mellitus. Vascular health and risk management. 2007;3(6):853.

91. Sharma S, Schaper N, Rayman G. Microangiopathy: Is it relevant to wound healing in diabetic foot disease? Diabetes Metab Res Rev. 2020;36:e3244.

92. Varga Z, et al. Endothelial cell infection and endotheliitis in COVID-19. The Lancet. 2020;395(10234):1417-8. 
93. Benz K, Amann K. Thrombotic microangiopathy: new insights. Curr Opin Nephrol Hypertens. 2010;19(3):242-7.

94. $\mathrm{Ma} \mathrm{C}$, et al. Effects of intensive insulin therapy on plasma nitric oxide and endothelin-1 levels in patients undergoing cardiac surgery under cardiopulmonary bypass. Zhonghua wai ke za zhi [Chinese journal of surgery]. 2008;46(6):443-5.

95. Dandona $P$, et al. Insulin inhibits intranuclear nuclear factor $\kappa B$ and stimulates IкB in mononuclear cells in obese subjects: evidence for an anti-inflammatory effect? J Clin Endocrinol Metab. 2001;86(7):3257-65.

96. Sun Q, Li J, Gao F. New insights into insulin: The anti-inflammatory effect and its clinical relevance. World J Diabetes. 2014;5(2):89.

97. Maddaloni E, Buzzetti R. Covid-19 and diabetes mellitus: unveiling the interaction of two pandemics. Diabetes/Metabolism Res Rev. 2020;e33213321.

98. Liu B, et al. Can we use interleukin-6 (IL-6) blockade for coronavirus disease 2019 (COVID-19)-induced cytokine release syndrome (CRS)? J Autoimmun. 2020;111:102452.

99. Lebovitz HE. Thiazolidinediones: the forgotten diabetes medications. Curr DiabRep. 2019;19(12):151.

100. Pfützner A, et al. High-sensitivity C-reactive protein predicts cardiovascular risk in diabetic and nondiabetic patients: effects of insulin-sensitizing treatment with pioglitazone. J Diabetes Sci Technol. 2010;4(3):706-16.

101. Guaraldi G, et al. Tocilizumab in patients with severe COVID19: a retrospective cohort study. The Lancet Rheumatology. 2020;2(8):e474-84.

102. Marfella R, et al. Negative impact of hyperglycaemia on tocilizumab therapy in Covid-19 patients. Diabetes \& Metabolism. 2020.

103. Malek M, et al. Diabetes Management during the COVID-19 Pandemic: An Iranian Expert Opinion Statement. Arch Iran Med. 2020;23(8):564-7.

104. Zhou G, et al. Role of AMP-activated protein kinase in mechanism of metformin action. J Clin Invest. 2001;108(8):1167-74.

105. Plattner F, Bibb JA. Serine and threonine phosphorylation. In: Basic Neurochemistry. Elsevier; 2012. p. 467-92.

106. Liu J, et al. AMPK: a balancer of the renin-angiotensin system. Biosci Rep, 2019;39(9):BSR20181994.

107. Ursini F, et al. COVID-19 and diabetes: Is metformin a friend or foe? Diabetes Res Clin Pract. 2020;164:108167.

108. Pal R, Bhadada SK. Should anti-diabetic medications be reconsidered amid COVID-19 pandemic? Diabetes Res Clin Pract. 2020;163:108146.

109. David Hopkins M. Diabetes, obesity and COVID-19: A complex interplay.

110. Scheen AJ, Marre M, Thivolet . Prognostic factors in patients with diabetes hospitalized for COVID-19: Findings from the CORONADO study and other recent reports. Diabetes \& Metabolism. 2020.

111. Luo P, et al. Metformin Treatment Was Associated with Decreased Mortality in COVID-19 Patients with Diabetes in a Retrospective Analysis. Am J Trop Med Hygiene. 2020; tpmd200375.

112. Petrie JR, Rossing PR, Campbell IW. Metformin and cardiorenal outcomes in diabetes: A reappraisal. Diabetes Obes Metab. 2020;22(6):904-15.

113. Jiao Y, Wang X, Luo Z. Preventive and (Neo) Adjuvant Therapeutic Effects of Metformin on Cancer, in Metformin. 2020, IntechOpen.

114. Singh AK, Singh R. Is Metformin ahead in the race as a repurposed host-directed therapy for patients with diabetes and COVID-19? Diabetes Res Clinical Prac. 2020.

115. Garcia E. Flumamine, a new synthetic analgesic and anti-flu drug. J Philipp Med Assoc. 1950;26(7):287.
116. Beisswenger P, Ruggiero-Lopez D. Metformin inhibition of glycation processes. Diabetes \& metabolism. 2003;29(4):6S95-6S103.

117. Sharma S, Ray A, Sadasivam B. Metformin in COVID-19: A possible role beyond diabetes. Diabetes res clinical prac. 2020; $164: 108183$.

118. Dalan R. Metformin, neutrophils and COVID-19 infection. Diabetes Res Clinical Prac. 2020.

119. Menendez JA. Metformin and SARS-CoV-2: mechanistic lessons on air pollution to weather the cytokine/thrombotic storm in COVID-19. Aging. 2020;12(10).

120. Bramante $\mathrm{C}$, et al. Observational study of metformin and risk of mortality in patients hospitalized with Covid-19. MedRxiv. 2020.

121. Esam Z. A proposed mechanism for the possible therapeutic potential of metformin in COVID-19. Diabetes Res Clinical Prac. $2020 ; 167$.

122. Kow CS, Hasan SS. Metformin use amid coronavirus disease 2019 pandemic. J Medic Virol. 2020.

123. Ursini F, et al. COVID-19 and diabetes: Is metformin a friend or foe? Diabetes research and clinical practice. 2020;164.

124. Bonnet F, Scheen A. Understanding and overcoming metformin gastrointestinal intolerance. Diabetes Obes Metab. 2017;19(4):473-81.

125. Raj VS, et al. Dipeptidyl peptidase 4 is a functional receptor for the emerging human coronavirus-EMC. Nature. 2013;495(7440):251-4.

126. Zou H, Zhu N, Li S. The emerging role of dipeptidyl-peptidase-4 as a therapeutic target in lung disease. Expert Opin Ther Targets. 2020;24(2):147-53.

127. Hopsu-Havu VK, Glenner GG. A new dipeptide naphthylamidase hydrolyzing glycyl-prolyl- $\beta$-naphthylamide. Histochemie. 1966;7(3):197-201.

128. Iacobellis G. COVID-19 and diabetes: can DPP4 inhibition play a role? diabetes research and clinical practice. 2020;162.

129. Omar BA, et al. Dipeptidyl peptidase 4 (DPP-4) is expressed in mouse and human islets and its activity is decreased in human islets from individuals with type 2 diabetes. Diabetologia. 2014;57(9):1876-83.

130. Pala L, Rotella C. The role of DPP4 activity in cardiovascular districts: in vivo and in vitro evidence. J diabetes res. 2013;2013.

131. Kim NH, Yu T, Lee DH. The nonglycemic actions of dipeptidyl peptidase-4 inhibitors. BioMed res international. 2014;2014.

132. Neumiller JJ. Differential chemistry (structure), mechanism of action, and pharmacology of GLP-1 receptor agonists and DPP-4 inhibitors. J Am Pharm Assoc. 2009;49(5):S16-29.

133. White JR. Dipeptidyl peptidase-IV inhibitors: pharmacological profile and clinical use. Clinical Diabetes. 2008;26(2):53-7.

134. Vankadari N, Wilce JA. Emerging COVID-19 coronavirus: glycan shield and structure prediction of spike glycoprotein and its interaction with human CD26. Emerging microbes \& infections. 2020;9(1):601-4.

135. Strollo R, Pozzilli P. DPP4 inhibition: preventing SARS-CoV-2 infection and/or progression of COVID-19? Diabetes/Metabolism Res Rev. 2020.

136. Yang W, et al. DPP-4 inhibitors and risk of infections: a metaanalysis of randomized controlled trials. Diabetes Metab Res Rev. 2016;32(4):391-404.

137. Kawasaki T, et al. DPP4 inhibition by sitagliptin attenuates LPSinduced lung injury in mice. American Journal of PhysiologyLung Cellular and Molecular Physiology. 2018;315(5):L834-45.

138. Tai W, et al. Characterization of the receptor-binding domain (RBD) of 2019 novel coronavirus: implication for development of RBD protein as a viral attachment inhibitor and vaccine. Cell Mol Immunol. 2020;17(6):613-20.

139. Pitocco D, et al. SARS-CoV-2 and DPP4 inhibition: is it time to pray for Janus Bifrons? Diabetes Res Clinical Prac. 2020;108162. 
140. Rizzo M, et al. Incretin-based therapies, glucometabolic health and endovascular inflammation. Curr Pharm Des. 2014;20(31):4953-60.

141. Lee YS, Jun HS. Anti-inflammatory effects of GLP-1-based therapies beyond glucose control. Mediators of inflamm. 2016;2016.

142. Viby N-E, et al. Glucagon-like peptide-1 (GLP-1) reduces mortality and improves lung function in a model of experimental obstructive lung disease in female mice. Endocrinology. 2013;154(12):4503-11.

143. Zhou F, et al. Liraglutide attenuates lipopolysaccharide-induced acute lung injury in mice. Eur J Pharmacol. 2016;791:735-40.

144. Bloodworth $\mathrm{MH}$, et al. Glucagon-like peptide 1 receptor signaling attenuates respiratory syncytial virus-induced type 2 responses and immunopathology. J Allergy Clinical Immunol. 2018;142(2):683-687. e12.

145. Smith U. Pioglitazone: mechanism of action. Int J Clin Pract Suppl. 2001;121:13-8.

146. Zhang W-Y, et al. Pioglitazone inhibits the expression of inflammatory cytokines from both monocytes and lymphocytes in patients with impaired glucose tolerance. Arterioscler Thromb Vasc Biol. 2008;28(12):2312-8.

147. Kutsukake M, et al. Pioglitazone attenuates lung injury by modulating adipose inflammation. J surgical res. 2014;189(2):295-303.

148. Carboni E, Carta AR, Carboni E. Can pioglitazone be potentially useful therapeutically in treating patients with covid-19? Med hypotheses. 2020;109776.

149. Bonnet F, Scheen A. Effects of SGLT2 inhibitors on systemic and tissue low-grade inflammation: The potential contribution to diabetes complications and cardiovascular disease. Diabetes Metab. 2018;44(6):457-64.

150. Heerspink HJ, et al. Canagliflozin reduces inflammation and fibrosis biomarkers: a potential mechanism of action for beneficial effects of SGLT2 inhibitors in diabetic kidney disease. Diabetologia. 2019;62(7):1154-66.

151. Åstrand A, et al. Dapagliflozin-lowered blood glucose reduces respiratory P. aeruginosa infection in diabetic mice.

152. Pharm SoC-mgDSS SAa. https://www.sps.nhs.uk/articles/summaryof-covid-19-and-medicines-guidance-diabetes/ (Accessed June 15.

153. Mukherjee JJ, Gangopadhyay KK, Ray S. Management of diabetes in patients with COVID-19. Lancet Diabetes Endocrinol. 2020;8(8):666.

154. Fodor G. Primary prevention of CVD: treating dyslipidemia. Am Fam Physician. 2011;83(10):1207.

155. Nelson RH. Hyperlipidemia as a risk factor for cardiovascular disease. Prim Care. 2013;40(1):195-211.

156. Bornstein SR, et al. Endocrine and metabolic link to coronavirus infection. Nat Rev Endocrinol. 2020;16(6):297-8.

157. Petrakis D, et al. Obesity - a risk factor for increased COVID19 prevalence, severity and lethality (Review). Mol Med Rep. 2020;22(1):9-19.

158. Hariyanto TI, Kurniawan A. Dyslipidemia is associated with severe coronavirus disease 2019 (COVID-19) infection. Diabetes Metab Syndr. 2020;14(5):1463-5.

159. Fessler MB, Summer RS. Surfactant lipids at the host-environment interface. Metabolic sensors, suppressors, and effectors of inflammatory lung disease. Am j resp cell molecular biol. 2016;54(5):624-635.

160. Schmidt NM, et al. Cholesterol-modifying drugs in COVID-19. Oxford Open Immunol. 2020;1(1):iqaa001.

161. Gowdy KM, Fessler MB. Emerging roles for cholesterol and lipoproteins in lung disease. Pulm Pharmacol Ther. 2013;26(4):430-7.

162. Tall AR, Yvan-Charvet L. Cholesterol, inflammation and innate immunity. Nat Rev Immunol. 2015;15(2):104-16.

163. Meher G, Bhattacharjya S. Membrane Cholesterol Modulates Oligomeric Status and Peptide-Membrane Interaction of Severe Acute Respiratory Syndrome Coronavirus Fusion Peptide. 2019;123(50):10654-62.
164. Soy M, et al. Cytokine storm in COVID-19: pathogenesis and overview of anti-inflammatory agents used in treatment. Clin Rheumatol. 2020;39(7):2085-94.

165. Wei X, et al. Hypolipidemia is associated with the severity of COVID-19. J Clinical Lipidol. 2020.

166. Funderburg, N.T. and N.N. Mehta . Lipid Abnormalities and Inflammation in HIV Inflection. Curr HIV/AIDS Rep. 2016;13(4):218-25.

167. Wei X, et al. Elevations of serum cancer biomarkers correlate with severity of COVID-19. 2020.

168. Grifoni A, et al. Targets of T cell responses to SARS-CoV-2 coronavirus in humans with COVID-19 disease and unexposed individuals. Cell. 2020.

169. Bojkova D, et al. Proteomics of SARS-CoV-2-infected host cells reveals therapy targets. Nature. 2020;1-8.

170. Tian S, et al. Pulmonary Pathology of Early-Phase 2019 Novel Coronavirus (COVID-19) Pneumonia in Two Patients With Lung Cancer. J Thorac Oncol. 2020;15(5):700-4.

171. Light RW, et al. Pleural effusions: the diagnostic separation of transudates and exudates. Ann Intern Med. 1972;77(4):507-13.

172. Kim J-A, et al. Role of lipotoxicity in endothelial dysfunction. Heart Fail Clin. 2012;8(4):589-607.

173. Kumar A, et al. SARS-CoV-2 cell entry receptor ACE2 mediated endothelial dysfunction leads to vascular thrombosis in COVID19 patients. Med Hypotheses. 2020;145:110320-110320.

174. Singh RB, et al. Pathogenesis of atherosclerosis: A multifactorial process. Exp Clin Cardiol. 2002;7(1):40-53.

175. Huertas A, et al. Endothelial cell dysfunction: a major player in SARS-CoV-2 infection (COVID-19)? Eur Respir J. 2020;56(1):2001634.

176. Cao X, et al. Cholesterol: A new game player accelerating vasculopathy caused by SARS-CoV-2? 2020. 319(1):E197-e202.

177. Froldi G, Dorigo P. Endothelial dysfunction in Coronavirus disease 2019 (COVID-19): Gender and age influences. Med Hypotheses. 2020;144:110015-110015.

178. Gordon EM, et al. High-density Lipoproteins and Apolipoprotein A-I: Potential New Players in the Prevention and Treatment of Lung Disease. Front Pharmacol. 2016;7:323.

179. Karathanasis SK, et al. The Changing Face of HDL and the Best Way to Measure It. Clin Chem. 2017;63(1):196-210.

180. Deniz O, et al. Serum HDL-C levels, log (TG/HDL-C) values and serum total cholesterol/HDL-C ratios significantly correlate with radiological extent of disease in patients with communityacquired pneumonia. Clin Biochem. 2006;39(3):287-92.

181. McKechnie JL, Blish CA. The Innate Immune System: Fighting on the Front Lines or Fanning the Flames of COVID-19? Cell Host Microbe. 2020;27(6):863-9.

182. Wang D, et al. Correlation analysis between disease severity and clinical and biochemical characteristics of 143 cases of COVID19 in Wuhan, China: a descriptive study. 2020.

183. Sala F, Catapano AL, Norata GD. High density lipoproteins and atherosclerosis: emerging aspects. Journal of geriatric cardiology : JGC. 2012;9(4):401-7.

184. Kaji H. High-density lipoproteins and the immune system. J Lipids. 2013;2013:684903.

185. Wei C, et al. Cholesterol Metabolism--Impact for SARSCoV-2 Infection Prognosis, Entry, and Antiviral Therapies. medRxiv. 2020

186. Shen B, et al. Proteomic and Metabolomic Characterization of COVID-19 Patient Sera. Cell. 2020;182(1):59-72.e15.

187. Khovidhunkit W, et al. Cholesterol efflux by acute-phase high density lipoprotein: role of lecithin: cholesterol acyltransferase. J Lipid Res. 2001;42(6):967-75.

188. Levy BD, et al. Protectin D1 is generated in asthma and dampens airway inflammation and hyperresponsiveness. J Immunol. 2007;178(1):496-502. 
189. Li X, et al. Clinical characteristics of 25 death cases with COVID-19: A retrospective review of medical records in a single medical center, Wuhan. China Int J Infect Dis. 2020;94:128-32.

190. Jahangiri A. High-density lipoprotein and the acute phase response. Curr Opin Endocrinol Diabetes Obes. 2010;17(2):156-60.

191. Han CY, et al. Serum amyloid A impairs the antiinflammatory properties of HDL. J Clin Invest. 2016;126(1):266-81.

192. Suzuki M, et al. High-density lipoprotein suppresses the type I interferon response, a family of potent antiviral immunoregulators, in macrophages challenged with lipopolysaccharide. Circulation. 2010;122(19):1919-27.

193. Kabouridis PS, Jury EC. Lipid rafts and T-lymphocyte function: implications for autoimmunity. FEBS Lett. 2008;582(27):3711-8.

194. Goldstein MR, Poland GA, Graeber CW. Are certain drugs associated with enhanced mortality in COVID-19? QJM. 2020;113(7):509-10.

195. Moore JB, June $\mathrm{CH}$. Cytokine release syndrome in severe COVID-19. Science. 2020;368(6490):473-4.

196. Yamashita CM, et al. Apolipoprotein E-Deficient Mice Are Susceptible to the Development of Acute Lung Injury. Respiration. 2014;87(5):416-27.

197. Umeki S. Decreases in Serum Cholesterol Levels in Advanced Lung Cancer. Respiration. 1993;60(3):178-81.

198. Janičko M, et al. Serum cholesterol is a significant and independent mortality predictor in liver cirrhosis patients. Ann Hepatol. 2013;12(4):413-9.

199. Pinal-Fernandez I, Casal-Dominguez M, Mammen AL. Statins: pros and cons. Med Clin (Barc). 2018;150(10):398-402.

200. Chansrichavala P, et al. Atorvastatin attenuates TLR4-mediated NF-kappaB activation in a MyD88-dependent pathway. Asian Pac J Allergy Immunol. 2009;27(1):49-57.

201. De Spiegeleer A, et al. The Effects of ARBs, ACEis, and Statins on Clinical Outcomes of COVID-19 Infection Among Nursing Home Residents. J Am Med Dir Assoc. 2020;21(7):909-914.e2.

202. Choi GJ, Kim HM, Kang H. The Potential Role of Dyslipidemia in COVID-19 Severity: an Umbrella Review of Systematic Reviews. Journal of Lipid and Atherosclerosis. 2020;9(3):435.

203. Khan AR, et al. The role of statins in prevention and treatment of community acquired pneumonia: a systematic review and metaanalysis. PLoS ONE. 2013;8(1):e52929.

204. Altun I, et al. Effect of statins on endothelial function in patients with acute coronary syndrome: a prospective study using adhesion molecules and flow-mediated dilatation. J Clin Med Res. 2014;6(5):354-61.

205. Gelosa P, et al. The role of HMG-CoA reductase inhibition in endothelial dysfunction and inflammation. Vasc Health Risk Manag. 2007;3(5):567-77.

206. Varga Z, et al. Endothelial cell infection and endotheliitis in COVID-19. Lancet. 2020;395(10234):1417-8.

207. Spann NJ, Glass CK. Sterols and oxysterols in immune cell function. Nat Immunol. 2013;14(9):893-900.

208. Spann N, Glass C. Sterols and oxysterols in immune cell function. Nat Immunol. 2013;14:893-900.

209. Cyster JG, et al. 25-Hydroxycholesterols in innate and adaptive immunity. Nat Rev Immunol. 2014;14(11):731-43.

210. Zhang X-J, et al. In-Hospital Use of Statins Is Associated with a Reduced Risk of Mortality among Individuals with COVID-19. Cell Metab. 2020;32(2):176-187.e4.

211. Popescu CI, et al. Hepatitis $\mathrm{C}$ virus life cycle and lipid metabolism. Biology (Basel). 2014;3(4):892-921.

212. Ali N, et al. Fluvastatin interferes with hepatitis $\mathrm{C}$ virus replication via microtubule bundling and a doublecortin-like kinasemediated mechanism. PLoS ONE. 2013;8(11):e80304.

213. Wang $\mathrm{C}$, et al. Identification of FBL2 as a geranylgeranylated cellular protein required for hepatitis $\mathrm{C}$ virus RNA replication. Mol Cell. 2005;18(4):425-34.
214. Jiang S, Hillyer C, Du L. Neutralizing Antibodies against SARSCoV-2 and Other Human Coronaviruses. Trends Immunol. 2020;41(5):355-9.

215. Astuti I, Ysrafil. Severe Acute Respiratory Syndrome Coronavirus 2 (SARS-CoV-2): An overview of viral structure and host response. Diabetes Metab Syndr. 2020. 14(4): p. 407-412.

216. Tikoo $\mathrm{K}$, et al. Tissue specific up regulation of ACE2 in rabbit model of atherosclerosis by atorvastatin: role of epigenetic histone modifications. Biochem Pharmacol. 2015;93(3):343-51.

217. Wösten-van Asperen RM, et al. Imbalance between pulmonary angiotensin-converting enzyme and angiotensin-converting enzyme 2 activity in acute respiratory distress syndrome. Pediatr Crit Care Med. 2013;14(9):e438-41.

218. Lu Y, Liu DX, Tam JP. Lipid rafts are involved in SARS-CoV entry into Vero E6 cells. Biochem Biophys Res Commun. 2008;369(2):344-9.

219. Li GM, et al. Lipid rafts play an important role in the early stage of severe acute respiratory syndrome-coronavirus life cycle. Microbes Infect. 2007;9(1):96-102.

220. Jeon JH, Lee C. Cholesterol is important for the entry process of porcine deltacoronavirus. 2018;163(11):3119-24.

221. Sezgin E, et al. The mystery of membrane organization: composition, regulation and roles of lipid rafts. Nat Rev Mol Cell Biol. 2017;18(6):361-74.

222. Mansur A, et al. Impact of statin therapy on mortality in patients with sepsis-associated acute respiratory distress syndrome (ARDS) depends on ARDS severity: a prospective observational cohort study. BMC Med. 2015;13:128-128.

223. Makris D, et al. Effect of pravastatin on the frequency of ventilator-associated pneumonia and on intensive care unit mortality: open-label, randomized study. Crit Care Med. 2011;39(11):2440-6.

224. McAuley DF, et al. Simvastatin in the Acute Respiratory Distress Syndrome. N Engl J Med. 2014;371(18):1695-703.

225. Rosuvastatin for Sepsis-Associated Acute Respiratory Distress Syndrome. N Engl J Med. 2014;370(23):2191-200.

226. Calfee CS, et al. Acute respiratory distress syndrome subphenotypes and differential response to simvastatin: secondary analysis of a randomised controlled trial. Lancet Respir Med. 2018;6(9):691-8.

227. Sinha P, et al. Latent class analysis of ARDS subphenotypes: a secondary analysis of the statins for acutely injured lungs from sepsis (SAILS) study. Intensive Care Med. 2018;44(11):1859-69.

228. Reiner $\breve{Z}$, et al. Statins and the COVID-19 main protease: in silico evidence on direct interaction. Arch Med Sci. 2020;16(3):490-6.

229. Zhou Y, et al. Network-based drug repurposing for novel coronavirus 2019-nCoV/SARS-CoV-2. Cell discovery. 2020;6(1):1-18.

230. Marakasova ES, et al. Prenylation of viral proteins by enzymes of the host: Virus-driven rationale for therapy with statins and FT/GGT1 inhibitors. BioEssays. 2017;39(10):1700014.

231. Perucha E, et al. The cholesterol biosynthesis pathway regulates IL-10 expression in human Th1 cells. Nat Commun. 2019;10(1):498.

232. Schmidt NM, et al. Cholesterol-modifying drugs in COVID-19. Oxford Open Immunol. 2020. 1(1)

233. Varga Z, et al. Endothelial cell infection and endotheliitis in COVID-19. Lancet (London, England). 2020;395(10234):1417-8.

234. Eckard AR, McComsey GA. The role of statins in the setting of HIV infection. Curr HIV/AIDS Rep. 2015;12(3):305-12.

235. Castiglione V, et al. Statin therapy in COVID-19 infection. European Heart J-Cardiovascular Pharmacotherapy. 2020.

236. Banach $\mathrm{M}$, et al. Brief recommendations on the management of adult patients with familial hypercholesterolemia during the COVID-19 pandemic. Pharmacol Res. 2020;158:104891. 
237. Alleva LM, Cai C, Clark IA. Using Complementary and Alternative Medicines to Target the Host Response during Severe Influenza. Evid Based Complement Alternat Med. 2010;7(4):501-10.

238. Takano T, et al. The cholesterol transport inhibitor U18666A inhibits type I feline coronavirus infection. Antiviral Res. 2017;145:96-102.

239. Nie X, et al. Multi-organ proteomic landscape of COVID-19 autopsies. medRxiv. 2020.

240. Gordon DE, et al. A SARS-CoV-2 protein interaction map reveals targets for drug repurposing. Nature. 2020: p. 1-13.

241. Wei C, et al. Cholesterol Metabolism--Impact for SARSCoV-2 Infection Prognosis, Entry, and Antiviral Therapies. medRxiv. 2020.

242. Ohashi $\mathrm{H}$, et al. Multidrug treatment with nelfinavir and cepharanthine against COVID-19. bioRxiv. 2020.

243. Nomoto S, et al. Effect of Cepharanthin in preventing radiation induced normal tissue damage in prostate cancer. Gan to kagaku ryoho. Cancer \& chemotherapy. 2004 1;31(7):1063-6.

244. Bailly C. Cepharanthine: An update of its mode of action, pharmacological properties and medical applications. Phytomedicine. 2019;62:152956.

245. Rogosnitzky M, Danks R. Therapeutic potential of the biscoclaurine alkaloid, cepharanthine, for a range of clinical conditions. Pharmacol Rep. 2011;63(2):337-47.

246. Nakayama S, et al. Clinical evaluation of cepharanthin for chronic idiopathic thrombocytopenic purpura. [Rinsho Ketsueki] The Japanese J Clinical Hematol. 1992. 33(3):408-409.

247. Papazian L, et al. Effect of statin therapy on mortality in patients with ventilator-associated pneumonia: a randomized clinical trial. JAMA. 2013;310(16):1692-700.

248. Mokhtari T, et al. COVID-19 and multiorgan failure: A narrative review on potential mechanisms. J Mol Histol. 2020;51(6):613-28.

249. Hales CM, et al. Prevalence of obesity and severe obesity among adults: United States, 2017-2018. 2020.

250. $\mathrm{Ng} \mathrm{M}$, et al. Global, regional, and national prevalence of overweight and obesity in children and adults during 1980-2013: a systematic analysis for the Global Burden of Disease Study 2013. The lancet. 2014;384(9945):766-81.

251. Fischer-Posovszky P, Möller P. Das Fettgewebe im Fokus des Immunsystems: adipositasassoziierte Inflammation. Pathologe. 2020;41(3):224-9.

252. Louie JK, et al. A Novel Risk Factor for a Novel Virus: Obesity and 2009 Pandemic Influenza A (H1N1). Clin Infect Dis. 2011;52(3):301-12.

253. Dawood FS, et al. Estimated global mortality associated with the first 12 months of 2009 pandemic influenza A H1N1 virus circulation: a modelling study. Lancet Infect Dis. 2012;12(9):687-95.

254. Du RH, et al. Predictors of mortality for patients with COVID-19 pneumonia caused by SARS-CoV-2: a prospective cohort study. European Resp J. 2020. 55(5).

255. Kang YJ. Mortality rate of infection with COVID-19 in Korea from the perspective of underlying disease. Disaster medicine and public health preparedness. 2020: p. 1-3.

256. Ruan Q, et al. Clinical predictors of mortality due to COVID-19 based on an analysis of data of 150 patients from Wuhan. China Intensive care medicine. 2020;46(5):846-8.

257. Eckel RH, et al. 2013 AHA/ACC guideline on lifestyle management to reduce cardiovascular risk: a report of the American College of Cardiology/American Heart Association Task Force on Practice Guidelines. J Am College Cardiol. 2014. (25 Part B): p. 2960-2984.

258. Apovian CM. Obesity: definition, comorbidities, causes, and burden. Am J Manag Care. 2016;22(7 Suppl):s176-85.

259. Finer N, Garnett SP, Bruun JM. COVID-19 and obesity. Clin Obes. 2020;10(3):e12365.

260. KRÁLÍKOVÁ E. KORONAVIRUS A KOUŘENÍ. HYGIENA, 2020. 65(2): p. 78-79.
261. Watanabe M, et al. Obesity and SARS-CoV-2: A population to safeguard. Diabetes/Metabolism Research and Reviews. n/a(n/a): p. e3325.

262. Murugan AT, Sharma G. Obesity and respiratory diseases. Chron Respir Dis. 2008;5(4):233-42.

263. Puig-Domingo M, Marazuela M, Giustina A. COVID-19 and endocrine diseases. A statement from the European Society of Endocrinology. Endocrine. 2020 68(1):2-5.

264. Collaborators GBDO, et al. Health Effects of Overweight and Obesity in 195 Countries over 25 Years. N Engl J Med. 2017;377(1):13-27.

265. Stefan N, et al. Obesity and impaired metabolic health in patients with COVID-19. Nature Rev Endocrinol. 2020: p. 1-2.

266. Dixon AE, Peters U. The effect of obesity on lung function Expert Rev Respir Med. 2018;12(9):755-67.

267. Jones RL, Nzekwu M-MU. The effects of body mass index on lung volumes. Chest. 2006;130(3):827-33.

268. Collet F, et al. Physiologic correlates of dyspnea in patients with morbid obesity. Int J Obes. 2007;31(4):700-6.

269. Fleischmann E, et al. Tissue oxygenation in obese and non-obese patients during laparoscopy. Obes Surg. 2005;15(6):813-9.

270. Park HS, Park JY, Yu R. Relationship of obesity and visceral adiposity with serum concentrations of CRP, TNF-alpha and IL-6. Diabetes Res Clin Pract. 2005;69(1):29-35.

271. Vieira-Potter VJ. Inflammation and macrophage modulation in adipose tissues. Cell Microbiol. 2014;16(10):1484-92.

272. Karkhaneh M, et al. Association of serum complement C3 with metabolic syndrome components in normal weight obese women. J Diabetes Metab Disord. 2017;16(1):49.

273. Gralinski LE, et al. Complement activation contributes to severe acute respiratory syndrome coronavirus pathogenesis. MBio. 2018. 9(5)

274. Jose RJ, Manuel A. Does Coronavirus Disease 2019 Disprove the Obesity Paradox in Acute Respiratory Distress Syndrome? Obesity. 2020;28(6):1007-1007.

275. Yiu HH, Graham AL, Stengel RF. Dynamics of a cytokine storm. PLoS ONE. 2012;7(10):e45027.

276. Karlsson EA, Sheridan PA, Beck MA. Diet-induced obesity in mice reduces the maintenance of influenza-specific CD8+ memory T cells. J Nutr. 2010;140(9):1691-7.

277. Ahn S-Y, et al. The effect of lipopolysaccharide-induced obesity and its chronic inflammation on influenza virus-related pathology. Environ Toxicol Pharmacol. 2015;40(3):924-30.

278. Muscogiuri G, et al. Comentary: Obesity: The "Achilles heel" for COVID-19? Metabolism-Clinical and Experimental, 2020. 108.

279. Ryan PM, Caplice NM. Is Adipose Tissue a Reservoir for Viral Spread, Immune Activation, and Cytokine Amplification in Coronavirus Disease 2019? Obesity. 2020;28(7):1191-4.

280. Reinhold D, Brocke S. DPP4-directed therapeutic strategies for MERS-CoV. Lancet Infect Dis. 2014;14(2):100-1.

281. Zhang AJ, et al. Leptin mediates the pathogenesis of severe 2009 pandemic influenza $\mathrm{A}(\mathrm{H} 1 \mathrm{~N} 1)$ infection associated with cytokine dysregulation in mice with diet-induced obesity. J Infect Dis. 2013;207(8):1270-80.

282. Huang Y, et al. Obesity in patients with COVID-19: a systematic review and meta-analysis. Metabolism. 2020: p. 154378.

283. Danziger J, et al. Obesity, acute kidney injury, and mortality in critical illness. Crit Care Med. 2016;44(2):328.

284. Gao F, et al. Obesity is a risk factor for greater COVID-19 severity. Diabetes Care. 2020.

285. Grant WB, et al. Evidence that vitamin D supplementation could reduce risk of influenza and COVID-19 infections and deaths. Nutrients. 2020;12(4):988.

286. Teymoori-Rad M, et al. The interplay between vitamin D and viral infections. Rev Med Virol. 2019;29(2):e2032. 
287. Robinson MK, et al. The relationship among obesity, nutritional status, and mortality in the critically ill. Crit Care Med. 2015;43(1):87-100.

288. Jia X, et al. Two Things about COVID-19 Might Need Attention. 2020, Preprints.org.

289. Zhou $\mathrm{P}$, et al. A pneumonia outbreak associated with a new coronavirus of probable bat origin. Nature. 2020;579(7798):270-3 .

290. Virdis A. Endothelial dysfunction in obesity: role of inflammation. High Blood Pressure \& Cardiovascular Prevention. 2016;23(2):83-5.

291. Kwaifa IK, et al. Endothelial Dysfunction in Obesity-Induced Inflammation: Molecular Mechanisms and Clinical Implications. Biomolecules. 2020;10(2):291.

292. Hajifathalian K, et al. Obesity is associated with worse outcomes in COVID-19: Analysis of Early Data From New York City. Obesity. 2020.

293. Michalakis K, Ilias I. SARS-CoV-2 infection and obesity: Common inflammatory and metabolic aspects. Diabetes \& Metabolic Syndrome: Clinical Res Rev. 2020 1;14(4):469-71.

294. Ryan DH, Ravussin E, Heymsfield S. COVID 19 and the patient with obesity-the editors speak out. Obesity. 2020

295. Dietz W, Santos-Burgoa C. Obesity and its Implications for COVID-19 Mortality. Obesity. 2020;28(6):1005-1005.

296. Ibrahim MM. Subcutaneous and visceral adipose tissue: structural and functional differences. Obes Rev. 2010;11(1):11-8.
297. Hussain A, et al. Obesity and mortality of COVID-19. Metaanalysis. Obesity res clinical prac. 2020.

298. Cai Q, et al. Obesity and COVID-19 severity in a designated hospital in Shenzhen. China Diabetes care. 2020;43(7):1392-8.

299. Simonnet A, et al. High prevalence of obesity in severe acute respiratory syndrome coronavirus-2 (SARS-CoV-2) requiring invasive mechanical ventilation. Obesity. 2020.

300. Aghili SMM, et al. Obesity in COVID-19 era, implications for mechanisms, comorbidities, and prognosis: a review and metaanalysis. Int J Obes (Lond). 2021: p. 1-19.

301. Busetto L, et al. Obesity and COVID-19: an Italian snapshot. Obesity. 2020.

302. Choon Lim Wong G, et al. Hallmarks of improved immunological responses in the vaccination of more physically active elderly females. Exercise immunol rev. 2019;25.

303. Payab M, et al. Development of a Novel Anti-Obesity Compound with Inhibiting Properties on the Lipid Accumulation in 3T3-L1 Adipocytes. Iran Biomed J. 2020;24(3):155-63.

304. Payab M, et al. Effect of the herbal medicines in obesity and metabolic syndrome: A systematic review and meta-analysis of clinical trials. Phytother Res. 2020;34(3):526-45.

Publisher's Note Springer Nature remains neutral with regard to jurisdictional claims in published maps and institutional affiliations. 